\title{
The influence of executive capacity on selective attention and subsequent processing
}

\author{
Kirk R. Daffner ${ }^{1 *}$, Elise C. Tarbi ${ }^{1}$, Anna E. Haring ${ }^{1}$, Tatyana Y. Zhuravleva ${ }^{1}$, Xue Sun $^{1}$, \\ Dorene M. Rentz ${ }^{1}$ and Phillip J. Holcomb ${ }^{2}$ \\ Center for Brain/Mind Medicine, Division of Cognitive and Behavioral Neurology, Department of Neurology, Brigham and Women's Hospital, \\ Harvard Medical School, Boston, MA, USA \\ 2 Department of Psychology, Tufts University, Medford, MA, USA
}

Edited by:

Burkhard Pleger, Max Planck Institute for Human Cognitive and Brain Sciences, Germany

Reviewed by:

Burkhard Pleger, Max Planck Institute for Human Cognitive and

Brain Sciences, Germany

Tilmann A. Klein, Max Planck

Institute for Human Cognitive and

Brain Sciences, Germany

*Correspondence:

Kirk R. Daffner, Center for

Brain/Mind Medicine, Division of

Cognitive and Behavioral Neurology,

Department of Neurology,

Brigham and Women's Hospital,

Harvard Medical School,

221 Longwood Avenue, Boston,

MA 02115, USA.

e-mail: kdaffner@partners.org
Recent investigations that suggest selective attention (SA) is dependent on top-down control mechanisms lead to the expectation that individuals with high executive capacity (EC) would exhibit more robust neural indices of SA. This prediction was tested by using event-related potentials (ERPs) to examine differences in markers of information processing across 25 subjects divided into two groups based on high vs. average EC, as defined by neuropsychological test scores. Subjects performed an experimental task requiring $S A$ to a specified color. In contrast to expectation, individuals with high and average EC did not differ in the size of ERP indices of SA: the anterior Selection Positivity (SP) and posterior Selection Negativity (SN). However, there were substantial differences between groups in markers of subsequent processing, including the anterior N2 (a measure of attentional control) and the P3a (an index of the orienting of attention). EC predicted speed of processing at both early and late attentional stages. Individuals with lower EC exhibited prolonged SN, P3a, and P3b latencies. However, the delays in carrying out SA operations did not account for subsequent delays in decision making, or explain excessive orienting and reduced attentional control mechanisms in response to stimuli that should have been ignored. SN latency, P3 latency, and the size of the anterior N2 made independent contributions to the variance of EC. In summary, our findings suggest that current views regarding the relationship between top-down control mechanisms and SA may need refinement.

Keywords: selective attention, executive functions, event-related potentials, top-down control

\section{INTRODUCTION}

Previous models of attentional function viewed selective attention (SA) and working memory as being mediated by separate neurocognitive systems (Kahneman, 1973; Hirst, 1986; Wijers et al., 1989; Kok, 2000; Luck et al., 2000). However, the dominant theory now suggests that $\mathrm{SA}$ is primarily influenced by the executive control component of working memory. The current investigation tested this theory by deriving an index of executive capacity (EC) not linked to a particular experimental task but to performance on neuropsychologial tests, and by using event-related potential (ERP) measures of SA and subsequent processing.

Investigators have argued that the top-down control functions of WM allow individuals to actively maintain current stimulus processing priorities, which facilitates the processing of information most critical to task demands (Desimone and Duncan, 1995; Lavie et al., 2004; Sawaki and Katayama, 2008; Rutman et al., 2010). Within this framework, SA and WM are viewed as dependent on a shared pool of limited processing resources. In support of this model, research has suggested that competition for executive resources or diminished EC is associated with increased interference from distracter stimuli. For example, in a dual-task in which participants were required to ignore distracter faces while holding a sequence of digits in WM, high WM load led to increased processing of distracter faces (measured by augmented neural activity in visual association cortex) and interference effects on performance (measured by slower reaction time in the SA task) (de Fockert et al., 2001). Similarly, many studies have suggested that individuals with lower WM capacity carry out SA operations much less effectively than those with high capacity. For example, Vogel et al. (2005) divided subjects into high vs. low WM capacity groups and found that the low capacity group was less able to prevent the encoding and storage of distracter items, as measured electrophysiologically by what was labeled contralateral delay activity. They suggested that WM capacity strongly influences the efficiency of SA.

Most studies (e.g., Gazzaley et al., 2005, 2008; Vogel et al., 2005; Rutman et al., 2010; Zanto et al., 2010) that have examined the relationship between individual differences in WM and neural markers of SA have divided subject groups based on their performance on the particular experimental task employed. Several investigators have highlighted the disadvantages of this approach in functional imaging studies (Daselaar and Cabeza, 2005; Braver et al., 2010). The behavioral performance of subjects in an experiment is often dependent on the particular demands of a task, which can limit inferences about whether group differences in brain activity are restricted to the specific task or are the result 
of a stable capacity, such as executive control (Braver et al., 2010). Similarly, correlations between performance and neural activity cannot be readily generalized to different experimental conditions. Daselaar and Cabeza (2005) argue in favor of distinguishing high and low performing individuals on the basis of a battery of neuropsychological tasks that are standardized and, therefore, generalizable. In keeping with this approach, we derived an estimate of EC based on a set of standard neuropsychological tests, and defined subjects as having high or average capacity by comparing their performance with age-matched norms. Although there is no universally accepted operational definition of executive functions, we followed the suggestion of many investigators who emphasize processes that include working memory, initiation, monitoring, and inhibition, and advocate the use of at least several neuropsychological tests to assess this complex group of functions (Spreen and Strauss, 1998; Delis et al., 2001; Chan et al., 2008).

In the current study, participants with high and average EC performed a task requiring SA to color. Subjects were shown a series of red and blue letters. Under the color SA task, subjects were told to respond to target letters in a designated color (Attend), while ignoring stimuli in the other color (Ignore). Under the color-neutral attention task (Neutral), physically identical stimuli were presented, but subjects were told to respond to target letters that appeared in either color. The critical difference between the color-selective attention task and the color-neutral task is the additional requirement of selectivity (Daffner et al., 2012).

The anterior Selection Positivity (SP) and the posterior Selection Negativity (SN) were used as ERP markers of SA to color. These potentials exhibit an overlapping time course between $\sim 150$ and $\sim 350 \mathrm{~ms}$ post stimulus presentation. The anterior SP has been conceptualized either as a frontally mediated index of the motivational salience of a stimulus based on task relevance (Potts and Tucker, 2001; Riis et al., 2009) or as a marker of a detection process sensitive to stimulus features, such as color, orientation, or size, that have been specified by task instructions as being significant (Luck and Hillyard, 1994). The posterior SN reflects the activity of feature-selection areas of the extrastriate cortex that may represent the enhancement of sensory-perceptual processing of relevant stimulus features compared to irrelevant ones (Harter and Aine, 1984; Hillyard et al., 1998; Kopp et al., 2007). Inclusion of a color-neutral condition in our SA task also allowed us to make inferences about whether differences in these traditional early modulations of electrophysiological activity between the Attend and Ignore conditions reflected increased activity under the Attend condition, reduced activity under the Ignore condition, or both (Gazzaley et al., 2008; Daffner et al., 2012).

The excellent temporal resolution of ERPs was used to carefully track the impact of differences in the execution of SA operations on subsequent measures of cognitive control, orienting of attention, and decision making, as indexed by the N2, P3a, and P3b components, respectively. Theoretically, early selection serves to filter information available for later cognitive operations (Hirst, 1986; Neville and Lawson, 1987; Gazzaley et al., 2005; Vogel et al., 2005; Zanto and Gazzaley, 2009; Rutman et al., 2010). The anterior N2 was used as an index of cognitive control, reflecting mechanisms involved with the detection of response conflict or the inhibition of task-inappropriate responses (Falkenstein et al., 1999; Nieuwenhuis et al., 2003; Folstein and Van Petten, 2008; Kropotov et al., 2011). The P3a component served as a marker of the conscious aspect of the orienting response, which reflects the evaluation of events for determining whether they merit additional processing and subsequent action $^{1}$ (Daffner et al., 1998, 2003; Knight and Scabini, 1998; Friedman et al., 2001). The P3b component was used as an index of controlled processing resources allocated to decisionmaking or the updating of memory after a decision has been made (Wickens et al., 1983; Donchin and Coles, 1988; Sirevaag et al., 1989; Kok, 2001; Daffner et al., 2011).

The theory that SA is primarily influenced by top-down control mechanisms leads to the prediction that individuals with greater capacity for executive control, as measured by neuropsychological tests, would exhibit more robust markers of SA, as indexed by the larger amplitudes of the SP and SN components. It is important to elaborate upon why we believe that more effective SA would be associated with a larger SP and SN. After all, under many circumstances, the generation of ERP components with larger amplitudes does not represent the most optimal response. Individuals with more efficient processing capacity may be able to carry out task operations by appropriating fewer resources, which would be indexed by generating components with smaller amplitudes (Daffner et al., 2011). However, this framework does not apply to components indexing SA. The SP and SN reflect the difference in neural response between attending and ignoring stimuli. Absent or minimal difference between the attend and ignore conditions represents a failure of SA. In contrast, greater differentiation of neural activity to stimuli under attend vs. ignore conditions reflects the most appropriate response, which would be indexed by difference waves that have larger amplitudes. This thesis is supported by results from previous studies that have found subjects who perform better on experimental tasks involving SA generate larger differences in neural response between attend and ignore conditions (Gazzaley et al., 2005, 2008; Vogel et al., 2005).

The color-neutral task allowed our predictions to be refined further. Several investigators (e.g., Gazzaley et al., 2005; Zanto and Gazzaley, 2009) have found that failure to suppress neural activity to irrelevant stimuli is more closely associated with differences in performance on WM tasks than the inability to enhance neural activity to relevant stimuli. Therefore, one might expect that average capacity individuals would exhibit less reduction than their high capacity counterparts in neural activity under the

\footnotetext{
${ }^{1}$ In our view, although the P3a component can be evoked by a stimulusdriven, bottom-up mechanism, it does not simply index an automatic process. There is evidence to suggest that the P3a is dependent on a pool of limited processing resources and likely reflects the activity of an executive control system (Friedman et al., 2001; Barcelo et al., 2006; Chong et al., 2008). However, even if one holds a more traditional view that the P3a component reflects an automatic orienting response, it would be of interest to map the relationship between early selection and the subsequent orienting of attention, as is done in this paper.
} 
Ignore relative to the Neutral condition. In general, the inability to find differences between individuals with high and average EC in measures of the SP and SN would suggest a need to modify current views regarding the relationship between executive control and SA.

We considered two competing hypotheses regarding differences in the magnitude of the anterior N2 between high and average capacity subjects. On the one hand, there is evidence to suggest that individuals who perform more accurately on experimental tasks (with fewer false alarms) generate a larger anterior N2 (Falkenstein et al., 1999; Folstein and Van Petten, 2008), a component which presumably signals the need to withhold a response to non-target stimuli that share features with target events. Based on these data, one might predict that high capacity individuals would exhibit a larger anterior N2 to "target-like" stimuli under the Ignore condition, when participants must exercise cognitive control to manage response conflict. On the other hand, based on the existing literature, we expected high capacity subjects to exhibit more effective early selection mechanisms, which might reduce the need to exercise later cognitive control. This framework predicts that high capacity individuals would exhibit an attenuated anterior N2 response to target-like stimuli under the Ignore condition, whereas average capacity individuals would need to exert cognitive control at this later stage because of their less successful early SA. Consistent with suggestions in the literature (Cabeza et al., 2002; Friedman, 2003; Riis et al., 2008), we adopted the strategy that if differences in neural activity were found between cognitively high and average performers, the pattern associated with the high performers would be interpreted as representing a more adaptive response. We also hypothesized that because of sub-optimal early selection mechanisms, average capacity individuals would produce a larger orienting response (P3a) and appropriate more decision-making resources (P3b) to target-like stimuli under the Ignore condition. This would result in average capacity individuals generating a smaller difference between the Ignore and the Attend conditions in the size of the $\mathrm{P} 3 \mathrm{a}$ and $\mathrm{P} 3 \mathrm{~b}$.

Finally, we expected that superior top down control in high capacity individuals would allow them to carry out task operations more rapidly than average capacity individuals, which would be indexed by earlier peak latencies of the ERP components. This result would be consistent with research that has found that high capacity or better performing subjects exhibit faster latencies (Polich et al., 1983; Walhovd and Fjell, 2002; Walhovd et al., 2005; Riis et al., 2008).

In summary, early filtering in the SA task is based on color and mediated by top-down control of early SA, as indexed by the SP and SN. We hypothesized that compared to young adults with average EC, those with high EC would be more proficient in the execution of top-down control. This would result in high capacity individuals generating larger overall differences in their neural response to stimuli under attend vs. ignore conditions, and more effective suppression of activity under ignore. This hypothesis leads to the expectation that high capacity individuals would generate larger amplitudes for the SP and SN components, as measured by comparing the Attend to the Ignore condition, and greater suppression of activity under the Ignore condition, as measured by comparing the Neutral to the Ignore condition. The ability of high capacity individuals to carry out pertinent operations more quickly would be associated with the generation of earlier latencies. More effective early filtering by high capacity individuals would also allow them to appropriate fewer resources to subsequent conscious orienting and decision making in response to target-like stimuli that are supposed to be ignored. Consistent with this idea, we anticipated that high capacity individuals would exhibit larger differences in P3a and P3b amplitude between the Attend and Ignore conditions. Based on the available literature, ambiguity remains regarding what to expect for the size of the anterior N2 in response to target-like events under the Ignore condition. If differences in the anterior N2 were found between the groups, the pattern of response exhibited by the high capacity subjects would be viewed as being the more advantageous.

\section{METHODS \\ PARTICIPANTS}

Subjects were recruited through advertisements in local newspapers, websites, and bulletin boards in the Boston metropolitan area. All subjects underwent informed consent approved by the Partners Human Research Committee and a detailed screening evaluation that included a structured interview to obtain a medical, neurological, and psychiatric history, a formal neurological examination, the completion of a neuropsychological test battery, and questionnaires surveying mood and socioeconomic status. To be included in this study, participants had to be 18-32 years old, English-speaking, have $\geq 12$ years of education, a Mini Mental State Exam (MMSE; Folstein et al., 1975) score $\geq 26$, and an estimated IQ on the American Modification of the National Adult Reading Test (AMNART; Ryan and Paolo, 1992) score $\geq 100$. Subjects were excluded if they had a history of CNS diseases or major psychiatric disorders based on DSM-IV criteria (American Psychiatric Association., 1994), a history of clinically significant medical diseases, corrected visual acuity worse than 20/40 (as tested using a Snellen wall chart), a history of clinically significant audiological disease, a Beck Depression Inventory (Beck and Steer, 1987) score of $\geq 10$, were unable to distinguish between the color red and blue, or focal abnormalities on neurological examination consistent with a CNS lesion. Subjects were paid for their time.

Critical to the goals of this study was an assessment of executive functions, which represent a collection of cerebral processes that exert top-down, volitional control over cognition and behavior (Spreen and Strauss, 1998; Heilman and Valenstein, 2003; Daffner and Searl, 2007). We selected tests that had wellestablished norms across a range of age groups (in anticipation of using the same battery to examine age-related changes). The neuropsychological tests of executive functions included: (1) Digit Span Backward subtest of the Wechsler Adult Intelligence ScaleIV (WAIS-IV; Wechsler, 2008), which measures maintenance and manipulation operations of WM; (2) Controlled Oral Word Association Test (COWAT; Ivnik et al., 1996), which indexes initiation, self-generation, and monitoring; (3) WAIS-IV LetterNumber Sequencing, which assesses maintenance, monitoring and manipulation; (4) WAIS-IV Digit-Symbol Coding, which 
assesses sustained attention/persistence, cognitive speed and efficiency; (5) Trail-Making Test Parts A and B (Reitan and Wolfson, 1985), which measures planning/sequencing, set shifting, and inhibition. Neuropsychological test scores were standardized using age-matched norms. EC was defined as the composite (mean percentile) score for all tests of executive function listed above. High capacity subjects scored in the top 3rd ( $\geq 67$ th percentile), while average capacity subjects scored in the middle 3 rd (33rd to 66th percentile).

Neuropsychological tests that do not evaluate executive functions were also given and included: (1) Matrix reasoning subtest of the WAIS-IV (Wechsler, 2008), which provides a measure of fluid intelligence; (2) Boston Naming test (Tombaugh and Hubley, 1997) and (3) Token test (Benton et al., 1994), which measure language functioning; (4) Logical Memory II subtest of the Wechsler Memory Scale-III (Wechsler, 1997), which tests verbal memory; and (5) Visual Form Discrimination (Benton et al., 1983), which provides a measure of complex visual perception. Overall performance on tests of non-executive functions was computed as the mean percentile score on these neuropsychological tests based on age-matched norms.

\section{EXPERIMENTAL PROCEDURES}

The experiment consisted of two related tasks: a color SA task from which Attend (A) and Ignore (I) conditions were extracted, and a color-neutral attention (NA) task from which Neutral (N) condition was derived. In both tasks, subjects were shown physically identical sets of stimuli that consisted of a series of letters presented in either the color red or the color blue and were asked to respond by button press to five specific target letters. In the SA task, subjects were instructed to pay attention to letters appearing in the designated color while ignoring letters appearing in the other color, and to respond by button press to target letters appearing in the designated color only. In the NA task, subjects were instructed to pay attention to all letters regardless of color. Under both tasks, subjects were asked to respond as quickly and as accurately as possible to target letters. Practice trials preceded each set of experimental trials. All subjects participated in both tasks, whose order was counterbalanced. Each task was presented during a different experimental session, separated by at least 2 weeks to reduce potential order effects. The hand used for the target response was counterbalanced across subjects, as was the attend color in the SA condition. Additionally, the five specific letters selected as targets differed between the NA and the SA tasks.

Each task included 800 stimulus trials divided into eight blocks. Under both tasks, stimuli appeared one at a time within a fixation box that remained on the screen at all times and subtended a visual angle of $\sim 3.5^{\circ} \times 3.5^{\circ}$ at the center of a highresolution computer monitor. Half of the stimuli appeared in the color red and half in the color blue, in randomized order. Target letter forms (SA: $7.5 \%$ in attend color; $7.5 \%$ ignore color; NA: $7.5 \%$ probability overall, $3.75 \%$ in each color) were five designated upper case letters and standard stimuli (SA: 70\% overall; $35 \%$ in each color; NA: $77.5 \%$ overall, $38.75 \%$ in each color) were any non-target upper case letters ${ }^{2}$. Fillers accounted for the remainder of the stimuli presented. Visual stimuli subtended an angle of $2.5^{\circ}$ along their longest dimension and were presented for $250 \mathrm{~ms}$. The inter-stimulus interval (ISI) varied randomly between 815 and 1015 ms (mean $\sim 915 \mathrm{~ms}$ ) (see Figure 1).

For analytic purposes, trials under the SA task were further categorized in terms of whether the stimuli presented were in the attend or the ignore color. The Attend condition consisted of all stimuli (standards and targets) in the designated color; the Ignore

\footnotetext{
${ }^{2}$ The percentage of stimuli designated as targets (requiring a response) was held constant across both tasks, encompassing $7.5 \%$ of total stimuli presented (60 of 800 trials). In the SA task, $15 \%$ of the total stimuli were target letter forms (120 of 800 trials), of which half were true target events in the attend color (60 of 400 trials) and half were target-like events in the ignore color ( 60 of 400 trials). In the NA task, the percentage of stimuli designated as targets (requiring a response) remained the same (60 of 800 trials or $7.5 \%$ ), with 30 targets in one color (3.75\% of total stimuli presented) and 30 targets in the other color (3.75\% of total stimuli presented). Target letter forms were replaced by standard letter forms to accommodate this difference.
}

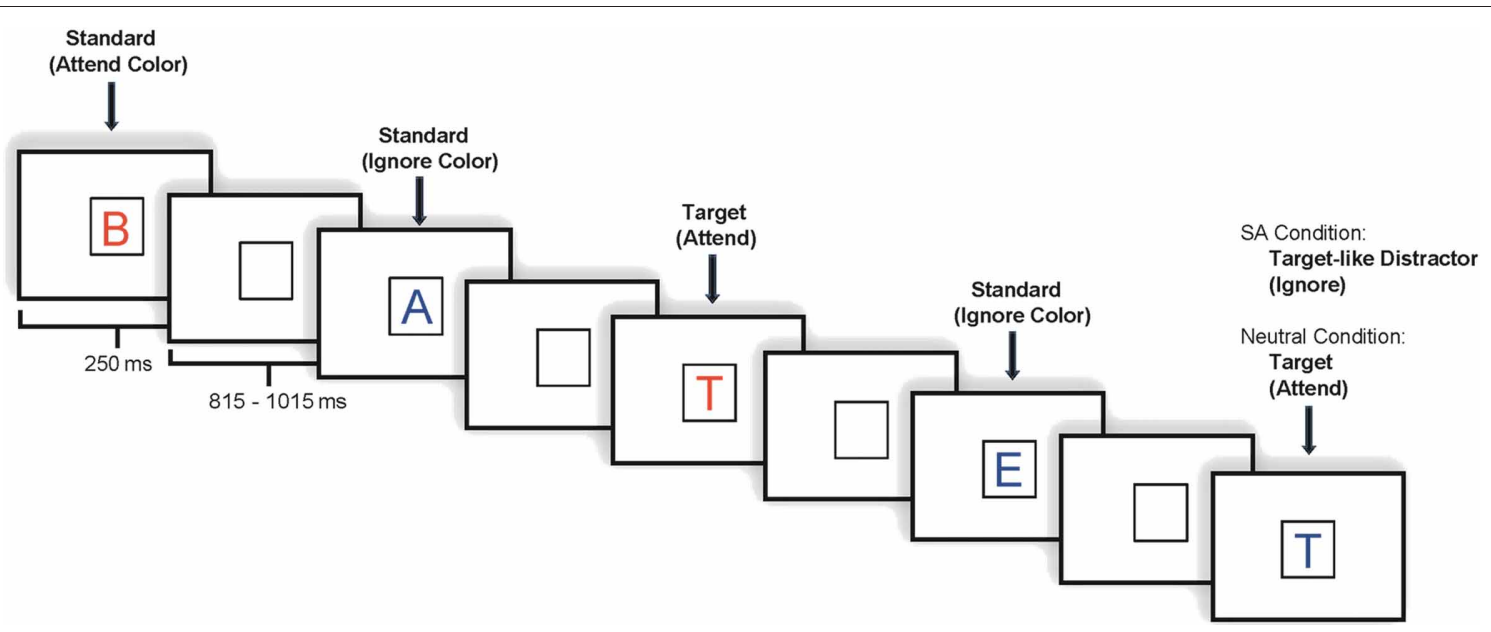

FIGURE 1 | Illustration of an experimental run. 
condition consisted of all stimuli (standards and targets) in the non-designated color. We refer to the five designated "target" letters appearing under the Ignore condition as "target-like" since subjects were not supposed to respond to them.

Consistent with theories about early selection, we expected that under the color-selective attention task, subjects would initially filter input on the basis of the most easily identifiable physical characteristic (color) and then continue to process more complex features (letter forms) of stimuli in the relevant color in order to identify targets (Hillyard and Munte, 1984; Looren et al., 1988; Daffner et al., 2012) [See Daffner et al. (2012) for a detailed discussion of the process model underlying task performance in this experimental paradigm].

\section{ERP RECORDINGS}

An ActiveTwo electrode cap (Behavioral Brain Sciences Center, Birmingham, UK) was used to hold to the scalp a full array of 128 Ag-AgCl BioSemi (Amsterdam, The Netherlands) "active" electrodes whose locations were based on a pre-configured montage. Electrodes were arranged in equidistant concentric circles from International 10-20 system position Cz. Active electrodes are amplified through the electrode at the source. In addition to the 128 electrodes on the scalp, six mini bio-potential electrodes were placed over the left and right mastoid, beneath each eye, and next to the outer canthi of the eyes to check for eye blinks and vertical and horizontal eye movements. EEG activity was digitized at a sampling rate of $512 \mathrm{~Hz}$.

\section{DATA ANALYSIS}

Mean reaction time (RT) and accuracy rates were measured separately in the SA and NA tasks. A response was considered a hit if it occurred between 200 and $1000 \mathrm{~ms}$ after stimulus presentation. Target stimuli correctly responded to (Target Hits) and stimuli incorrectly identified as targets (False Alarms) were measured in order to determine an overall accuracy score (Percent Target Hits - Percent False Alarms). Behavioral results under the SA and NA tasks were compared using analysis of variance (ANOVA), with task as the within-subject variable and EC as the between-subject variable.

EEG data were analyzed using ERPLAB (www.erpinfo.org/ erplab) and EEGLAB (Delorme and Makeig, 2004; http://sccn. ucsd.edu/eeglab) toolboxes that operate within the MATLAB framework. Raw EEG data were resampled to $256 \mathrm{~Hz}$ and referenced off-line to the algebraic average of the right and left mastoids. EEG signal was filtered using an IIR filter with a bandwidth of $0.03-40 \mathrm{~Hz}$ ( $12 \mathrm{~dB} /$ octave roll-off). Eye artifacts were removed through an independent component (IC) analysis. Individual bad channels were corrected with the EEGLAB interpolation function. EEG epochs for the two stimulus types (standard stimuli, target hits/target-like stimuli) across three conditions (Attend, Ignore, Neutral) were averaged separately. The sampling epoch for each trial lasted for $1200 \mathrm{~ms}$, including a $200 \mathrm{~ms}$ pre-stimulus period that was used to baseline correct the ERP epochs. Trials were discarded from the analyses if they contained baseline drift or movement artifacts greater than $90 \mu \mathrm{V}$. Only trials with correct responses were included in the analyses.
Regions of Interest (ROIs) across the scalp were designated and labeled Centro-Frontal (CF), Left Anterior Lateral (LAL), Right Anterior Lateral (RAL), Left Anterior Medial (LAM), Right Anterior Medial (RAM), Left Posterior Medial (LPM), Right Posterior Medial (RPM), Left OccipitoTemporal (LOT), Right Occipito-Temporal (ROT), and CentroOccipital (CO) (see Figure 2). Each region reflected a cluster of seven electrode sites. To determine whether there were antero-postero differences in the latency of the P3 component, we computed values at five midline sites $(\mathrm{FPz}, \mathrm{Fz}, \mathrm{Cz}, \mathrm{Pz}, \mathrm{Oz})$.

The temporal intervals used to measure the mean amplitude of the ERP components were chosen based on the peak latency results. The SN and the SP were analyzed using ANOVA, with attention condition (A, I, N) or difference wave condition (A-I, N-I), stimulus type (target, standard), and ROI as withinsubject variables, and $\mathrm{EC}$ as the between-subject variable. For the anterior N2 and P3 measures, we limited our examination to the response to target stimuli because we did not expect standard stimuli to elicit these components. Analyses that yielded significant interactions between EC and condition, stimulus type, or ROI resulted in planned contrasts between the levels of the variable. The Geisser-Greenhouse correction was applied for all repeated measures with greater than $1^{\circ}$ of freedom. Regression analyses were used to explore the relationship between markers of EC, early SA, later controlled processing, and behavioral performance.

Because of concerns about the potential for spatial and temporal overlap between the anterior $\mathrm{N} 2, \mathrm{P} 3 \mathrm{a}$, and $\mathrm{P} 3 \mathrm{~b}$ components in response to target stimuli, we employed the extended-Infomax ICA algorithm provided by the EEGLAB function runica.m (Bell and Sejnowski, 1995; Delorme et al., 2004) to further isolate specific components. Extended ICAs were separately applied to the datasets of the high and average capacity groups. Each dataset consisted of concatenated, unaveraged epochs in response to target stimuli under Attend, Ignore, and Neutral conditions, from all subjects within the cognitive capacity group. To ensure sufficient data for ICA decomposition, principal component analysis was initially applied to reduce the dimensionality of the data. ICs of interest can be identified by visual inspection of the spatial distribution and time course of their contribution to ERP activation (Delorme et al., 2004). ICs that corresponded to the anterior N2, P3a, and P3b were then back projected to the ERPs of individual participants (i.e., the ICA weights were applied to each subject's 128 electrode sites) (Onton et al., 2006). These computed ERP responses, reflecting the ICs, were measured and subjected to statistical analysis.

\section{RESULTS \\ PARTICIPANTS}

Thirteen average capacity and 12 high capacity subjects participated in this study. One additional average capacity and two high capacity subjects were excluded due to excessively noisy data. See Table 1 for subject characteristics, including demographic, neuropsychological test performance, and estimated IQ for each EC group, as well as pertinent statistical analyses. As expected, high capacity subjects had a higher EC percentile score than average capacity individuals $\left[t_{(23)}=6.48, p<0.00001\right]$. Subjects performed relatively consistently across the six tasks measuring EC. 


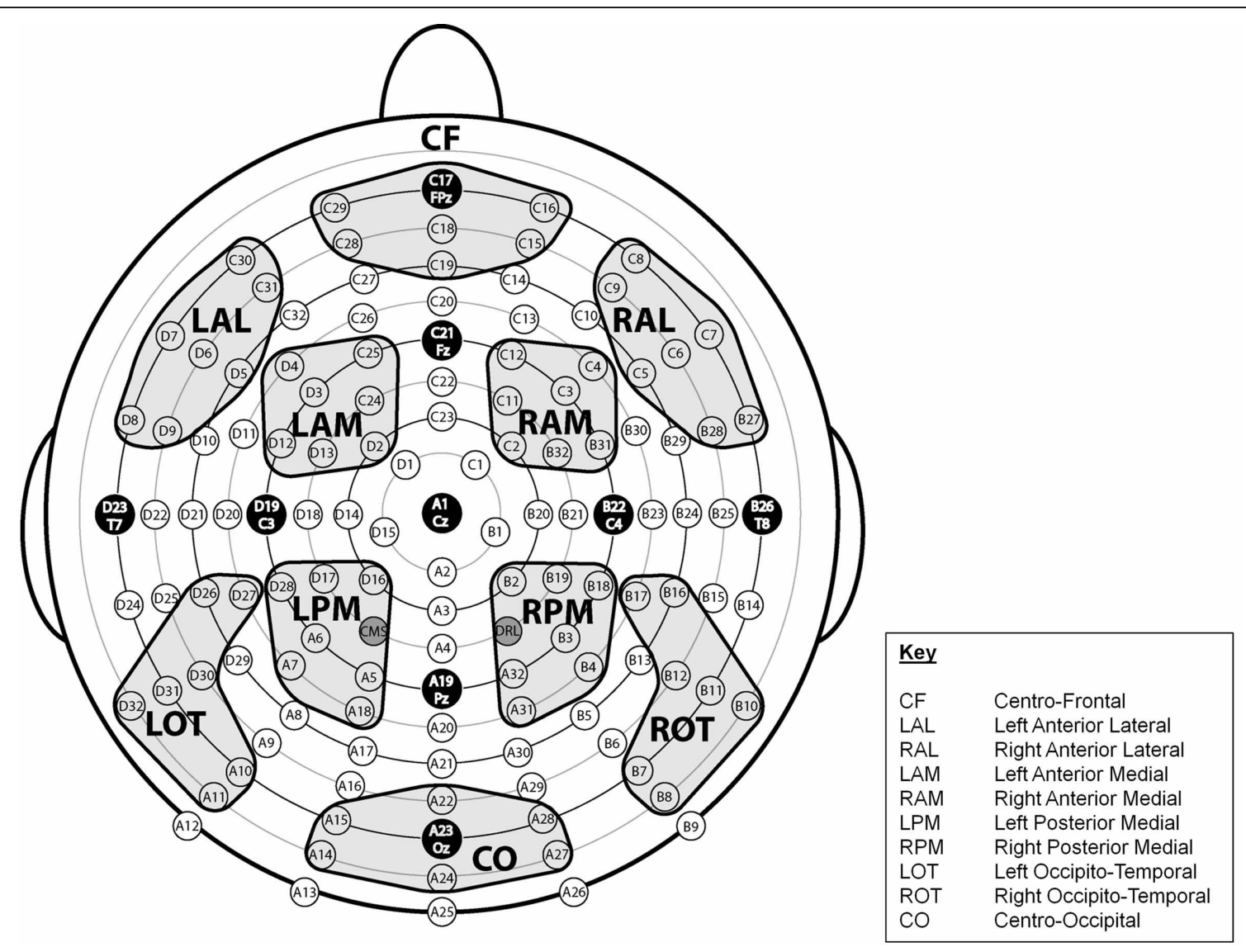

FIGURE 2 | Montage illustrating the location of 128 electrode sites and the 10 designated regions of interest (ROIs).

Table 1 | Subject characteristics [mean (SD)].

\begin{tabular}{lll}
\hline Dependent variable & High & Average \\
\hline Number of subjects & 12 & 13 \\
Gender (male: female) & $5: 7$ & $7: 6$ \\
Age & $22.6(1.7)$ & $22.6(2.7)$ \\
Years of education & $15.9(1.7)$ & $14.4(1.1)^{* *}$ \\
Executive function $^{a}$ & $80.3(8.4)$ & $54.0(11.5)^{* * *}$ \\
Non-executive function $^{b}$ & $73.6(8.1)$ & $66.3(17.9)$ \\
AMNART & $119.1(4.8)$ & $114.3(7.7)^{*}$ \\
\hline
\end{tabular}

${ }^{*} p<0.1 ; * * p<0.05 ; * * * p<0.01$.

${ }^{a}$ Average percentile performance on the following tests: Digit Span Backward, Controlled Oral Word Association Test, Letter-Number Sequencing, Digit-Symbol Coding, and Trail-Making Test Parts A and B.

${ }^{b}$ Average percentile performance on the following tests: Matrix reasoning, Boston Naming test, Token test, Logical Memory II, and Visual Form Discrimination.

On average, high capacity subjects performed above the 67 th percentile on approximately three-quarters of the tests, and average capacity subjects performed between the 33rd and 66th percentile on approximately two-thirds of the tests. High capacity individuals had more education than average capacity individuals $\left[t_{(23)}=\right.$ $2.58, p<0.02]$, and tended to have higher estimated IQs based on the AMNART $\left[t_{(23)}=1.84, p<0.08\right]$. However, the two groups demonstrated no differences in the mean percentile score on the five tests that do not assess EC $\left[t_{(23)}=1.30, p>0.2\right]$.

\section{BEHAVIOR}

The results of target hit rate, false alarm rate, and mean reaction time (RT) for each EC group are presented in Table 2, with pertinent statistical analyses noted. For mean reaction time, there was a strong trend toward an effect of EC $\left[F_{(1,23)}=3.96, p<0.06\right]$ and a robust effect of condition $\left[F_{(1,23)}=15.34, p<0.0007\right]$. High capacity individuals tended to perform more quickly than average capacity individuals. Subjects responded more slowly under the SA condition than the NA condition, with no interaction between condition and EC. For target accuracy, there was an effect of EC $\left[F_{(1,23)}=4.86, p<0.04\right]$, with high capacity individuals performing better than average capacity individuals. There was no effect of condition $(p>0.4)$ and no interaction between EC and condition $(p>0.9)$.

ERPs

This paper focused on the impact of EC on ERP markers of SA and subsequent processing. Main effects or interactions that did not include the factor of EC, as well as non-significant results, are not presented, unless of particular theoretical interest. Figure 3 presents grand average ERPs at the 10 ROIs for high capacity and 
Table 2 | Mean RT and accuracy for SA and NA tasks [mean (SD)].

\begin{tabular}{lccccc}
\hline $\begin{array}{l}\text { Behavioral } \\
\text { variable }\end{array}$ & \multicolumn{2}{c}{ High } & & \multicolumn{2}{c}{ Average } \\
\cline { 2 - 3 } \cline { 5 - 6 } & SA & NA & & SA & NA \\
\hline Mean RT & $588.0(41.8)$ & $550.9(59.1)$ & & $627.3(57.2)$ & $596.4(67.5)^{a, b}$ \\
Target hit \% & $92.3(7.0)$ & $94.0(6.5)$ & & $85.5(6.2)$ & $86.8(15.6)^{c}$ \\
False alarm \% & $0.5(0.4)$ & $0.2(0.2)$ & & $0.5(0.5)$ & $0.6(0.7)$ \\
\hline
\end{tabular}

$S A$, selective attention task; NA, color-neutral attention task; $R T$, response time.

Target hit \% = \# target hits / (\# target hits + \# target misses).

False alarm \% = (\# of responses to standard stimuli + \# of responses to target ignore stimuli) / (total \# standard stimuli + total \# of target ignore stimuli).

${ }^{a}$ Effect of condition.

${ }^{b}$ Trend toward effect of executive capacity $(p<0.07)$.

${ }^{c}$ Effect of executive capacity.

average capacity subjects in response to standard (3A) and target (3B) stimuli under the Attend, Ignore, and Neutral conditions.

\section{Early selection (anterior selection positivity and posterior selection negativity)}

First, we tested whether subjects with high EC generate a bigger difference in neural response between Attend and Ignore for the anterior SP and posterior SN components, and whether the latencies of these components are earlier.

The latency of the SP was measured as the local positive peak latency for the Attend-Ignore and Neutral-Ignore difference waves ${ }^{3}$ between 100 and $275 \mathrm{~ms}$ at the five anterior ROIs (CF, LAL, RAL, LAM, RAM). An ANOVA revealed an effect of stimulus type $\left[F_{(1,23)}=33.65, p<0.00001\right]$ that was present because the mean latency was earlier $(\sim 25 \mathrm{~ms})$ in response to standard than target stimuli. There was no effect of EC, and no interactions between EC and stimulus type or condition. The latency of the SN was measured as the local negative peak latency for the Attend Ignore and the Neutral - Ignore difference waves between 200 and $350 \mathrm{~ms}$ in response to both standard and target stimuli at the five posterior ROIs (LOT, ROT, LPM, RPM, CO). An ANOVA was noteworthy for an effect of EC $\left[F_{(1,23)}=4.92, p<0.04\right]$ that was present because the mean latency of high capacity subjects was earlier $(\sim 15 \mathrm{~ms})$ than that of average capacity individuals. This effect was not modified by difference wave condition or stimulus type. The difference between groups in SN latency was confirmed by a time-course analysis in which the mean amplitude was compared under Attend vs. Ignore, and under Neutral vs. Ignore for six $25 \mathrm{~ms}$ epochs between 200 and $350 \mathrm{~ms}$ at ROI LOT. The results are summarized in Table 3. In general, significant differences between conditions were observed for epochs that began at least $25 \mathrm{~ms}$ earlier for high capacity than average capacity subjects.

The size of the SP and SN was derived from the mean amplitude around the peak ( $\pm 50 \mathrm{~ms})$ for each component. The amplitude of the SP was measured as the mean value between 125 and $225 \mathrm{~ms}$ in response to standard stimuli and between

${ }^{3}$ For the SP, the local positive peak latency for the A-N difference wave was not measured because there were no consistent differences in amplitude between the Attend and Neutral conditions. For the SN, the local negative peak latency for the A-N difference wave was not measured for the same reason.
150 and $250 \mathrm{~ms}$ in response to target stimuli at the 5 anterior ROIs (Figure 3). Figure 4 highlights the grand average ERPs at the anterior ROI, CF, and Figure 5 presents surface potential maps of difference waves for Attend-Ignore, Neutral-Ignore, and Attend-Neutral for high and average capacity subjects in response to standard and target stimuli during the temporal interval of the SP. An ANOVA revealed an effect of condition $\left[F_{(2,46)}=7.64, p<0.005\right]$ that was not modified by stimulus type (no condition $\times$ stimulus type interaction) [Of note, the same pattern of response was observed for standards alone (effect of condition, $F_{(2,46)}=9.85, p<0.002$ ) and targets alone (effect of condition, $\left.F_{(2,46)}=3.80, p<0.05\right)$ ]. The condition effect was due to the mean amplitude being more positive under both the Attend condition and the Neutral condition than under the Ignore condition, with no difference between the Attend and Neutral conditions $[\mathrm{A}=\mathrm{N}>\mathrm{I}$; A $>$ I $(p<0.00006)$; $\mathrm{N}>\mathrm{I}(p<0.005)]$. Of particular interest, the magnitude of this effect was similar for the high and average capacity groups (no condition $\times \mathrm{EC}$ interaction; no condition $\times \mathrm{EC} \times \mathrm{ROI}$ interaction $)^{4}$.

The amplitude of the $\mathrm{SN}$ was measured as the mean value between 220 and $320 \mathrm{~ms}$ for high capacity and $230-330 \mathrm{~ms}$ for average capacity subjects in response to both standard and target stimuli at the five posterior ROIs (Figure 3). Figure 6 highlights the grand average ERPs at the posterior lateral ROI, LOT. Figure 7 presents surface potential maps of difference waves (A-I, N-I, A-N) for high and average capacity subjects in response to standard and target stimuli during the temporal interval of the SN. An ANOVA revealed an effect of condition $\left[F_{(2,46)}=7.32\right.$, $p<$ 0.003 , which was not modified by stimulus type [The same pattern of response was observed for standards alone (effect of condition, $F_{(2,46)}=6.03, p<0.006$ ) and targets alone (effect of condition, $\left.\left.F_{(2,46)}=4.64, p<0.02\right)\right]$. The effect of condition was due to more negative-going ERPs under both the Attend and Neutral conditions than under the Ignore condition, with no difference between the Attend and Neutral conditions $[\mathrm{A}=\mathrm{N}<\mathrm{I}$; $\mathrm{A}<\mathrm{I}(p<0.002) ; \mathrm{N}<\mathrm{I}(p<0.006)]$. This resulted in a large negativity (SN) for A-I and N-I (see Figure 7). The largest difference between conditions was observed at ROI LOT [condition $x$ ROI interaction, $\left.F_{(8,184)}=6.06, p<0.0002\right]$. Most importantly, the magnitude of the difference between conditions was similar for the high and average capacity groups.

In summary, for both the SP and SN components, the overall attentional modulation (A vs. I) and the pattern of enhancement and suppression $(\mathrm{A}=\mathrm{N}>\mathrm{I}$ for $\mathrm{SP}$ and $\mathrm{A}=\mathrm{N}<\mathrm{I}$ for $\mathrm{SN})$ did not differ for high vs. average capacity subjects. However, the onset and the peak of the $\mathrm{SN}$ component were delayed in average capacity individuals.

\footnotetext{
${ }^{4}$ Examination of the grand average ERP plots suggested that subjects with high executive capacity generated a larger anterior P2 component than subjects with average executive capacity. An ANOVA of the mean amplitude at the five anterior sites using the same intervals as the SP was consistent with this observation. Subjects with high executive capacity tended to have a larger $\mathrm{P} 2$ amplitude than subjects with average executive capacity $[F(1,23)=$ $3.86, p<0.07$ ], especially at ROIs LAM and RAM [EC $\times$ ROI interaction, $F(4,92)=4.74, p<0.01]$.
} 
A

Grand Average Waves

Standard Stimuli

High Capacity

Average Capacity

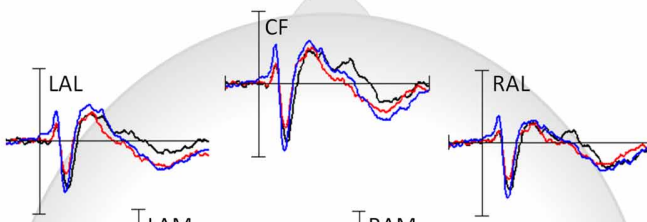

LAM
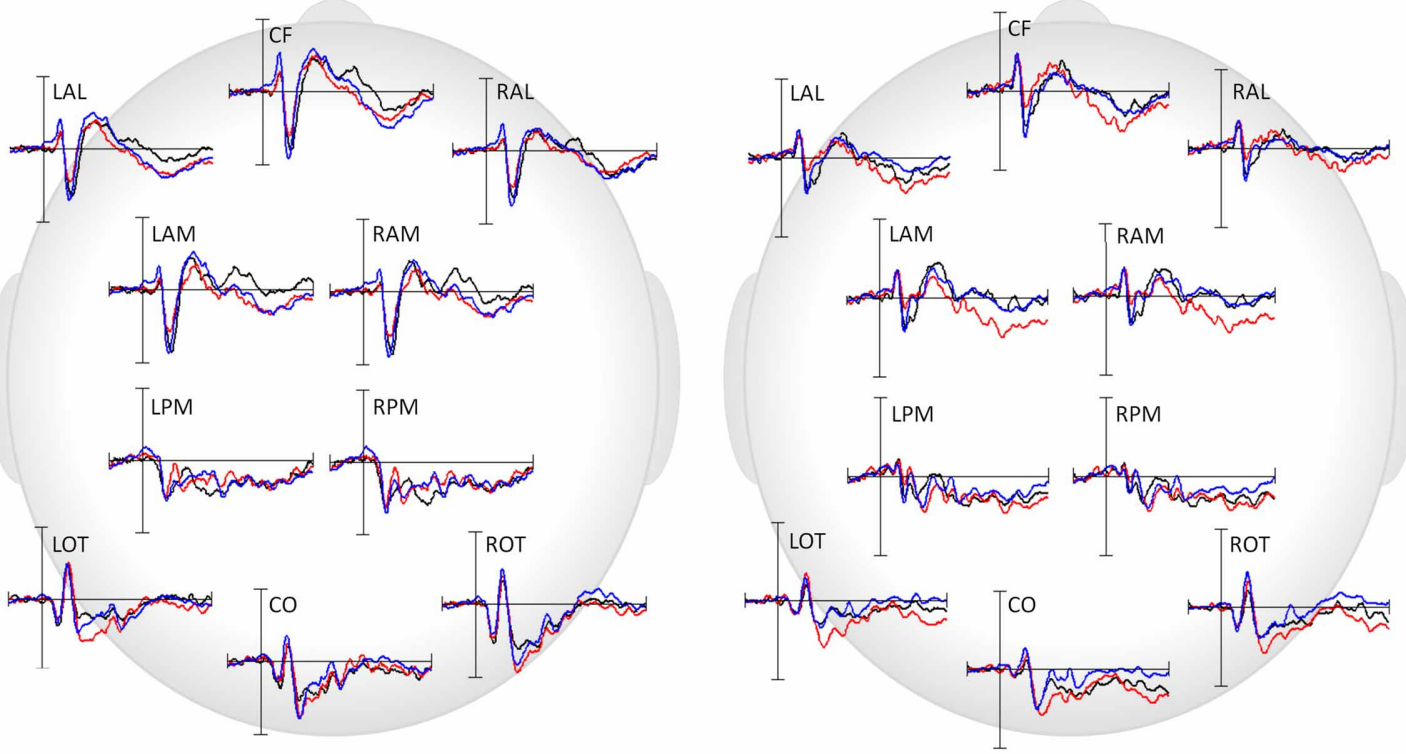

$-5$

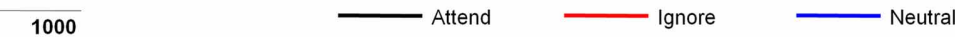

B

Grand Average Waves

Target Stimuli

High Capacity

Average Capacity
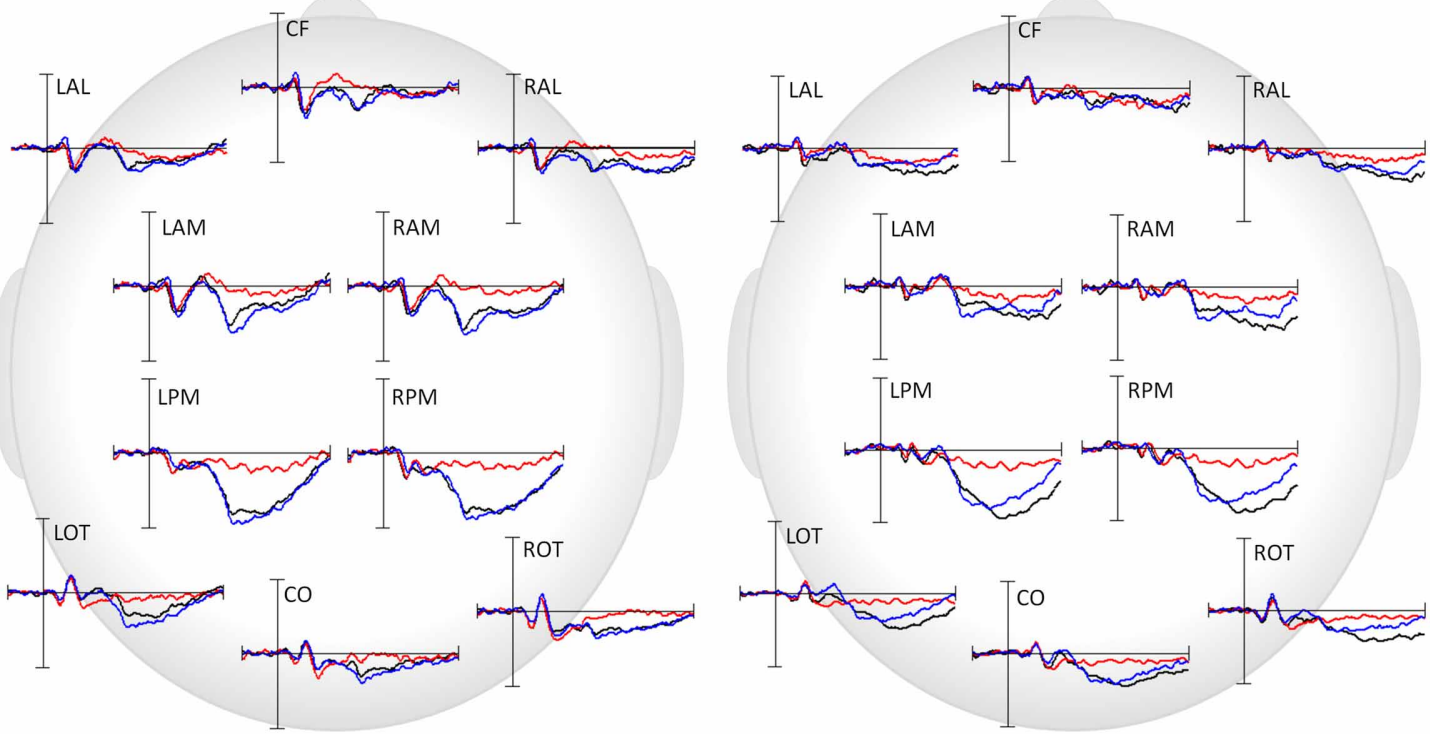

TLAM TRAM I
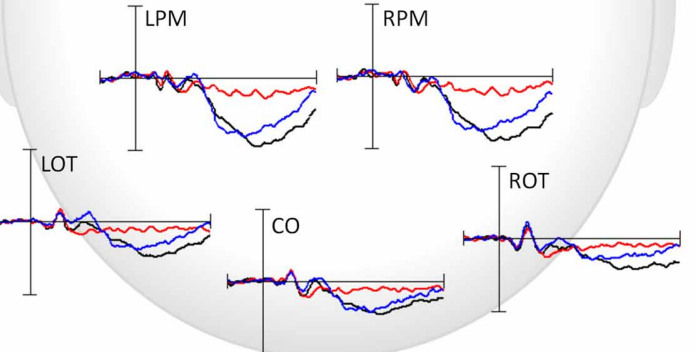

\begin{tabular}{l|l}
-12 & \\
\hline & 1000
\end{tabular}

Attend

Ignore

Neutral

FIGURE 3 | Grand average ERP responses under Attend, Ignore, and Neutral conditions at all 10 ROls for high capacity and average capacity subjects in response to $(A)$ standard stimuli and $(B)$ target stimuli. 
Table 3 | Selection negativity.

\begin{tabular}{|c|c|c|c|c|c|c|c|}
\hline & Group & \multicolumn{6}{|c|}{ Interval } \\
\hline \multirow[t]{2}{*}{ A vs. I } & High EC & $<0.05$ & $<0.01$ & $<0.01$ & $<0.01$ & $<0.05$ & \\
\hline & Ave EC & & $<0.01$ & $<0.01$ & $<0.01$ & $<0.01$ & $<0.05$ \\
\hline N vs. I & High EC & & $<0.05$ & $<0.05$ & $<0.05$ & $<0.05$ & $<0.05$ \\
\hline \multirow[t]{2}{*}{ A vs. I } & High EC & $<0.1$ & $<0.01$ & $<0.01$ & $<0.01$ & $<0.01$ & $<0.05$ \\
\hline & Ave EC & & & & $<0.05$ & 0.05 & \\
\hline \multirow[t]{2}{*}{ N vs. I } & High EC & $<0.05$ & $<0.01$ & $<0.01$ & $<0.05$ & $<0.05$ & \\
\hline & Ave EC & & & $<0.05$ & $<0.01$ & $<0.01$ & $<0.01$ \\
\hline
\end{tabular}

A, attend condition; I, ignore condition; N, neutral condition; EC, executive capacity.

Time course analysis of differences (p-values) between conditions for $25 \mathrm{~ms}$ epochs from 200 to $350 \mathrm{~ms}$.

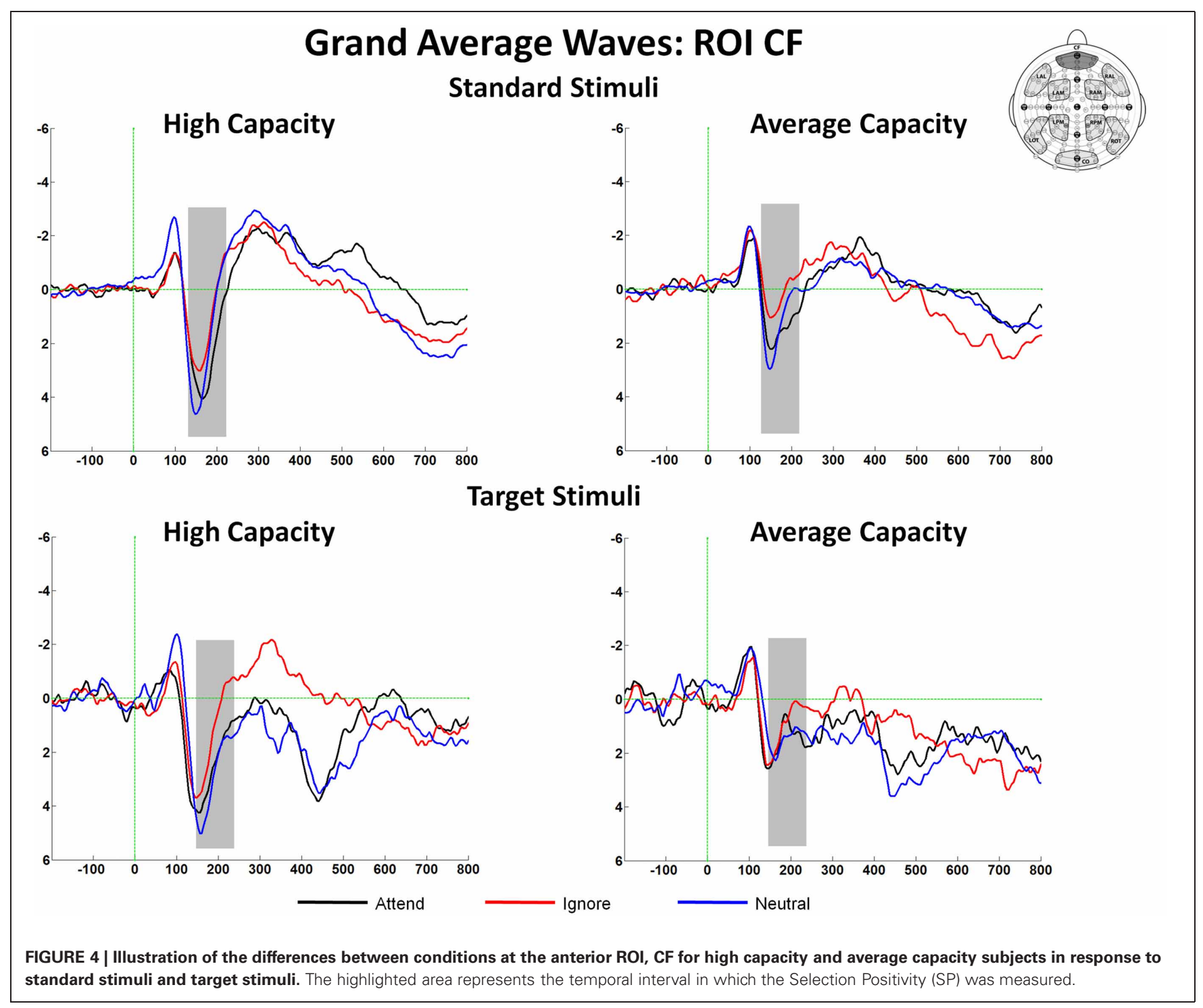




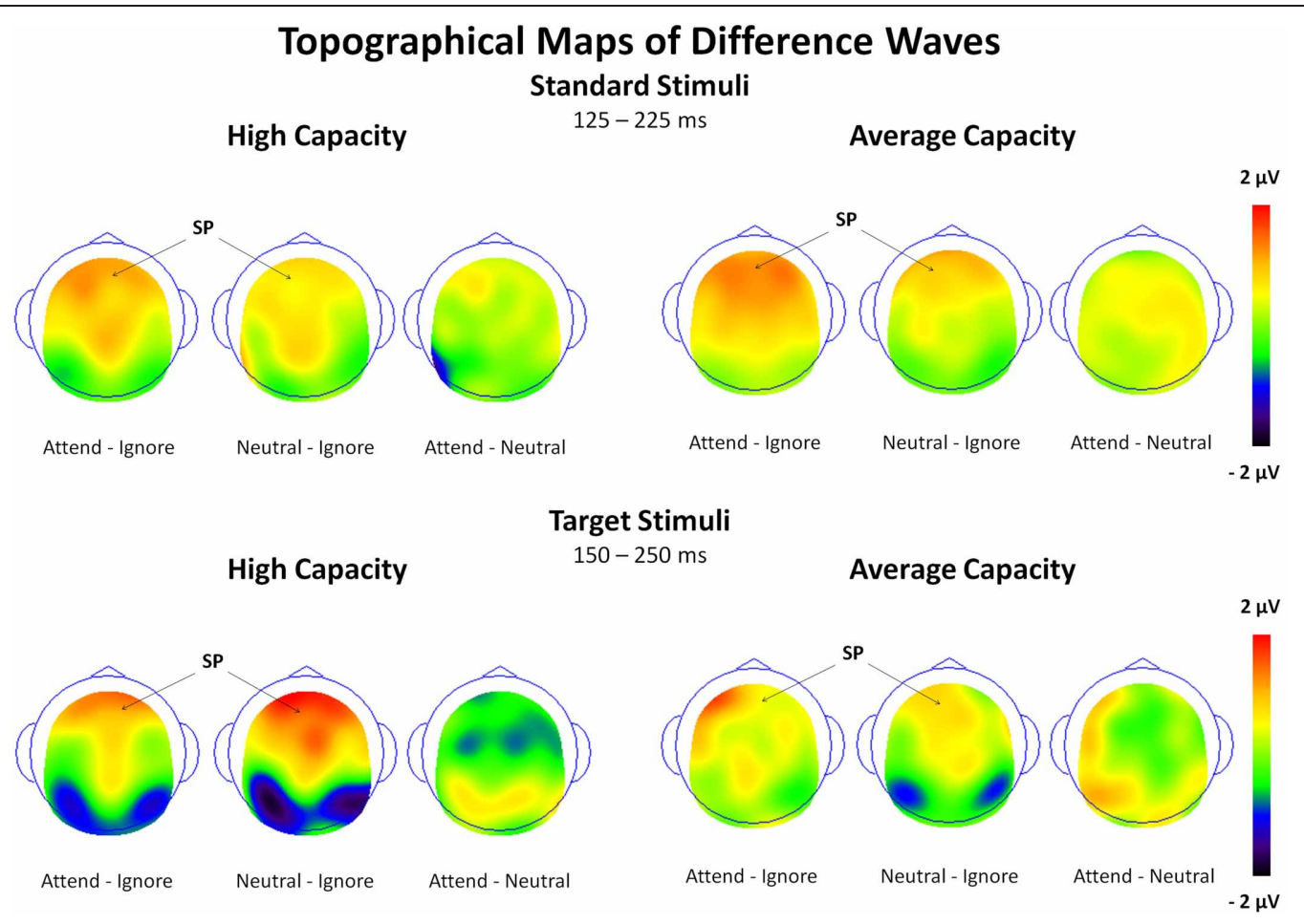

FIGURE 5 | Surface potential maps of difference waves under Attend-Ignore, Neutral-Ignore, and Attend-Neutral conditions for the SP interval for high capacity and average capacity subjects in response to standard stimuli and target stimuli. Arrows illustrate the presence of the Selection Positivity (SP).

\section{Anterior N2}

The latency of the anterior N2 was measured on grand average ERPs for the Attend, Ignore, and Neutral conditions as the local negative peak latency between 275 and $365 \mathrm{~ms}$ in response to target stimuli at anterior ROIs. There were no effects of EC, and no interactions between EC and condition or ROI. The amplitude of the anterior $\mathrm{N} 2$ in response to target and target-like stimuli was measured as the mean amplitude between 300 and $340 \mathrm{~ms}$ at anterior ROIs (Figure 3B), which represented the interval around the $\mathrm{N} 2$ peak $( \pm 20 \mathrm{~ms})$. The largest difference across conditions was observed at ROI RAM [condition $\times$ ROI interaction, $\left.F_{(8,184)}=4.05, p<0.005\right]$; therefore, subsequent analyses were focused on that ROI (see Figure 8A). An ANOVA revealed an interaction between $\mathrm{EC}$ and condition $\left[F_{(2,46)}=3.67, p<0.05\right]$. The interaction was present because for high capacity individuals, the mean amplitude of the anterior N2 in response to target-like stimuli under the Ignore condition was larger (more negative) than under the Attend or the Neutral conditions, with no difference between the latter two [effect of condition, $F_{(2,22)}=5.60$, $p<0.02 ; \mathrm{I}<\mathrm{A}=\mathrm{N} ; \mathrm{I}<\mathrm{A}(p<0.03) ; \mathrm{I}<\mathrm{N}(p<0.007)]$, whereas for average capacity performers, the mean amplitude did not differ across conditions ( $\mathrm{I}=\mathrm{A}=\mathrm{N}$; no effect of condition).

One concern is that apparent differences in the anterior N2 might simply reflect the impact of differences in the temporally overlapping positivity from the anteriorly distributed P3a, which, as reviewed below, also varied between groups. This potential confound was addressed by independent component analysis (ICA) which identified separate components corresponding to the anterior N2 and anterior P3a. ICA isolated an IC for each group that reflected a frontocentral negativity between 200 and $400 \mathrm{~ms}$, which was very suggestive of an anterior N2 (see Figure 9). Statistical analysis was performed on the back-projected ERP activations of the identified N2 IC. The latency of the backprojected N2 was measured as the local negative peak between 200 and $400 \mathrm{~ms}$. The anterior N2 for both the high and average capacity groups peaked around $290 \mathrm{~ms}$. An ANOVA around the peak $( \pm 50 \mathrm{~ms})$ was most notable for an effect of ROI $\left[F_{(9,207)}=\right.$ 8.64, $p<0.003]$ and an interaction between EC and condition $\left[F_{(2,46)}=5.53, p<0.02\right]$. The effect of ROI was present because the N2 was largest at fronto-central regions, ROIs CF, LAM, RAM, which did not differ across the two groups [No ROI $\times$ EC interaction, $\left.F_{(9,207)}=2.36, p>0.12\right]$. The interaction between EC and condition was due to high performers generating an anterior N2 under the Ignore condition that was much larger (more negative) than under the Attend or Neutral conditions [effect of condition, $F_{(2,22)}=12.12, p<0.002 ; \mathrm{I}<\mathrm{A}=\mathrm{N} ; \mathrm{I}<\mathrm{A}$ $(p<0.003) ; \mathrm{I}<\mathrm{N}(p<0.005)]$. In contrast, for average capacity individuals, there was no effect of condition $\left[F_{(2,24)}=2.37\right.$, $p>0.13 ; \mathrm{I}=\mathrm{A}=\mathrm{N} ; \mathrm{I} \geq \mathrm{A}(p>0.07) ; \mathrm{I} \geq \mathrm{N}(p>0.12)]$.

In summary, the pattern of response was similar for the grand average and IC back-projected results. In contrast to average capacity subjects, high capacity subjects exhibited a much more differentiated response across conditions. The high capacity group generated a considerably larger anterior N2 response to target-like stimuli under the Ignore condition than to target stimuli under the Attend and Neutral conditions. 


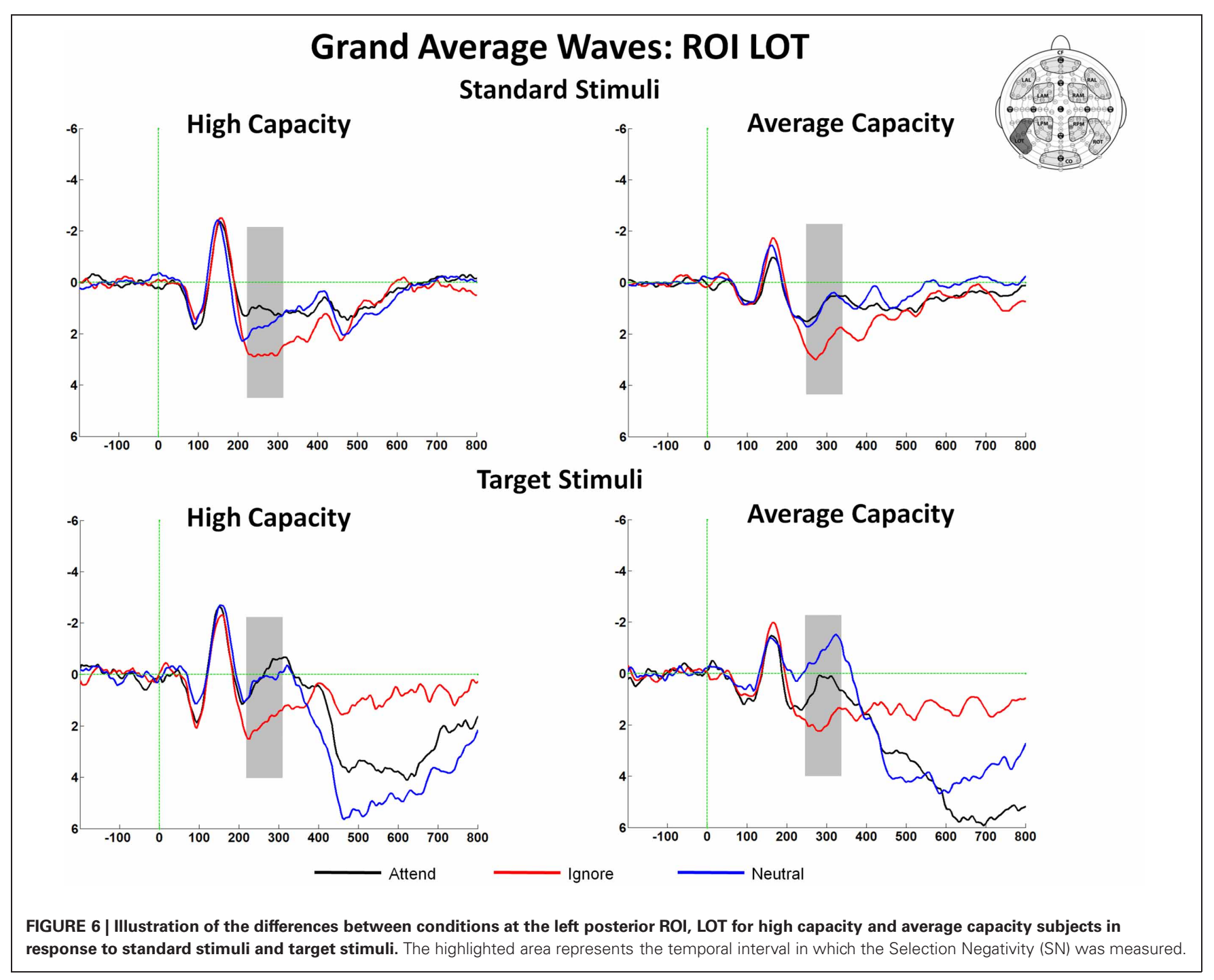

\section{P3 component}

The latency of the $\mathrm{P} 3$ component in response to target stimuli was measured as the local positive peak latency across 5 midline sites $(\mathrm{FPz}, \mathrm{Fz}, \mathrm{Cz}, \mathrm{Pz}, \mathrm{Oz}$ ) between 350 and $750 \mathrm{~ms}$ for the grand average waves under the Attend and Neutral conditions, as well as for the difference waves (A-I, N-I). An ANOVA for the P3 latency for the grand averages under Attend and Neutral conditions revealed an effect of EC $\left[F_{(1,23)}=4.50, p<0.05\right]$ and of electrode site $\left[F_{(4,92)}=3.94, p<0.04\right]$, but no effect of condition. The effect of EC was due to high capacity subjects generating an earlier P3 latency ( $\sim 54 \mathrm{~ms}$ ) than average capacity subjects. This effect was of a similar magnitude across midline sites (no EC $\times$ site interaction) (Of interest, the differences between groups in P3 latency remained after controlling for $\mathrm{SN}$ latency ${ }^{5}$ ). The electrode site effect was present because anterior sites had earlier P3 latencies

\footnotetext{
${ }^{5}$ Because the SN latency was not modified by condition or stimulus type, a subject's average SN latency collapsed across difference wave condition (A-I, $\mathrm{N}-\mathrm{I}$ ) and stimulus type was used as an index of his/her SN latency in ANOVAs or regression analyses that controlled for SN latency.
}

than posterior sites (e.g., Fz peaked $\sim 52 \mathrm{~ms}$ earlier than $\mathrm{Pz}$ ). An ANOVA of the P3 latency for the difference waves (A-I, N-I) yielded the same pattern of response ${ }^{6}$.

The observed earlier latency at frontal sites suggested that anterior regions may have reflected activity of the P3a component,

${ }^{6}$ An ANOVA of the P3 difference waves also revealed an effect of executive capacity $[F(1,23)=4.69, p<0.05]$ and of electrode site $[F(4,92)=8.68$, $p<0.00001]$, and an interaction between difference wave condition and executive capacity $[F(1,23)=5.11, p<0.04]$, but no effect of difference wave condition. The effect of executive capacity was due to high capacity subjects generating an earlier P3 latency $(\sim 42 \mathrm{~ms})$ than average capacity subjects (The differences between groups in P3 latency of the differences waves remained after controlling for SN latency). The difference in P3 latency between high and average capacity individual was of similar magnitude across midline sites (no EC $\times$ site interaction). The electrode site effect was present because anterior sites had earlier P3 latencies than posterior sites (e.g., Fz peaked $\sim 74$ ms earlier than $\mathrm{Pz}$ ). The interaction between executive capacity and difference wave condition was present because the difference in P3 latency between high and average capacity individuals was larger under the A-I than under the N-I difference waves. 


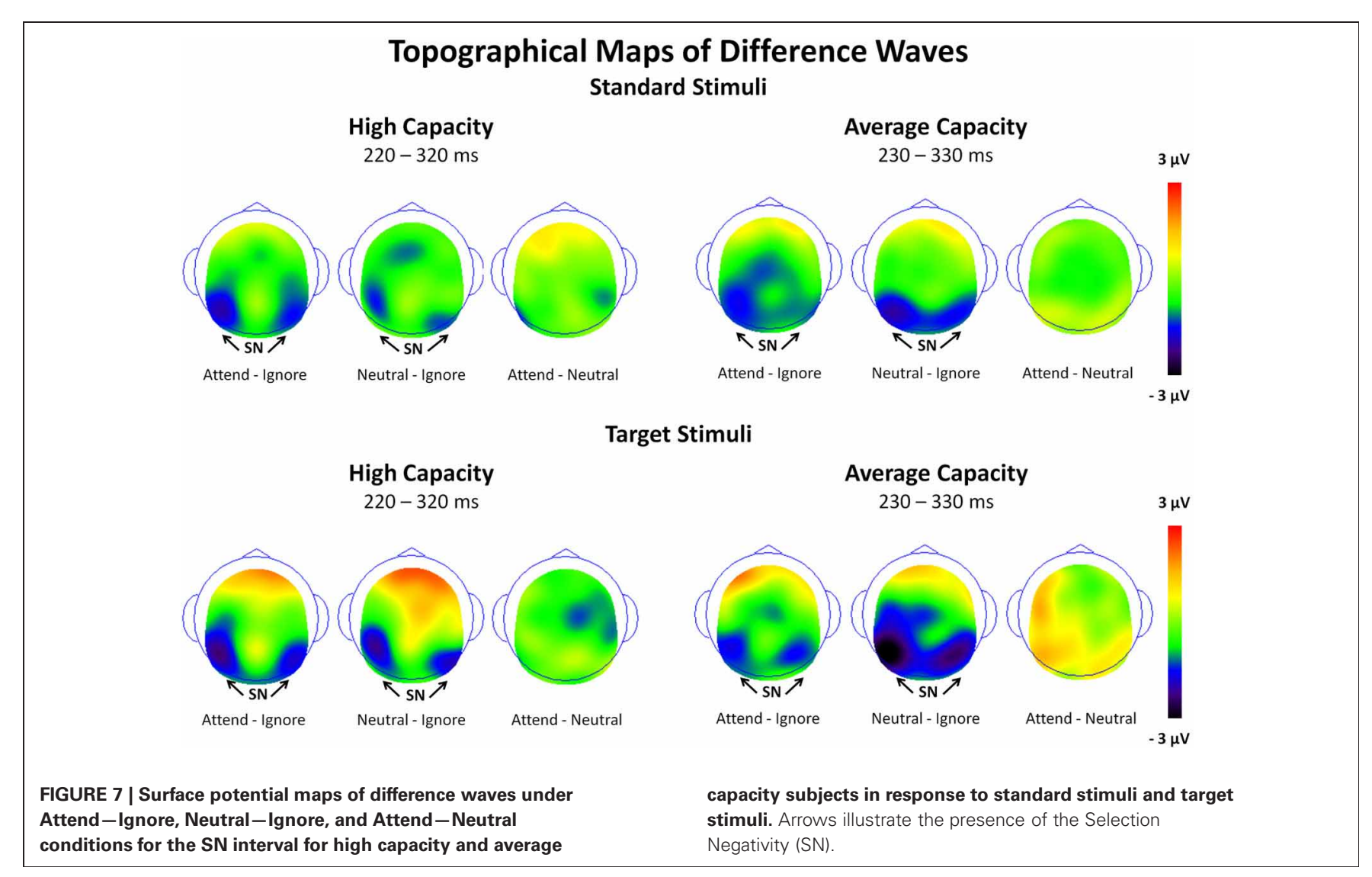

an anteriorly distributed waveform that peaks earlier than the posteriorly distributed P3b component (Knight and Scabini, 1998). Analytically, this issue was approached in two ways. First, the mean amplitude was measured at an earlier interval of $400-500 \mathrm{~ms}$ (P3a) and at a later interval of $500-600 \mathrm{~ms}$ (P3b). Second, we identified P3a and P3b components using ICA. Between 400 and $500 \mathrm{~ms}$, the largest effect across conditions was observed at fronto-central and centro-posterior ROIs (RAM, LAM, RPM, LPM); therefore, our subsequent analyses focused on these regions [condition $\times$ ROI interaction, $F_{(18,414)}=7.68$, $p<0.00001]$. An ANOVA ( 3 condition $\times 2$ group) revealed an effect of condition $\left[F_{(2,46)}=35.58, p<0.0001\right]$ and a trend toward an interaction between condition and $\operatorname{EC~}\left[F_{(2,46)}=\right.$ $2.95, p<0.07]$. The effect of condition was present because the amplitude of the P3a was larger in response to target stimuli under the Attend and Neutral conditions than to target-like stimuli under the Ignore condition, with no differences between the Attend and Neutral conditions $[\mathrm{A}=\mathrm{N}>\mathrm{I}$; A $>\mathrm{I}(p<$ $0.0001) ; \mathrm{N}>\mathrm{I}(p<0.0001)]$. The condition by EC interaction reflected the fact that the magnitude of the difference in the P3a amplitude between the Attend and Ignore conditions was larger for the high capacity than the average capacity subjects [condition (A vs. I) $\times$ EC interaction, $\left.F_{(1,23)}=6.32, p<0.02\right]^{7}$ (see Figure 8A).

\footnotetext{
${ }^{7}$ This result remained significant after controlling for differences in $\mathrm{SN}$ latency.
}

Between 500 and $600 \mathrm{~ms}$, the largest effect across conditions was observed at centro-posterior ROIs (RPM, LPM); therefore, our analyses focused on these regions [condition $\times$ ROI interaction, $\left.F_{(18,414)}=12.54, p<0.00001\right]$. An ANOVA revealed an effect of condition $\left[F_{(2,46)}=50.93, p<0.00001\right]$ but no interaction between condition and EC $(p>0.5)$ (Figure 8B $)^{8}$.

We used ICA to confirm that our measures of $\mathrm{P} 3 \mathrm{a}$ and $\mathrm{P} 3 \mathrm{~b}$ represent the activity of separate components. ICA identified ICs for each group that were strongly suggestive of a P3a component (anteriorly distributed positivity with a time course showing increased activation between 300 and $500 \mathrm{~ms}$ ) and P3b component (posteriorly distributed positivity with a time course showing peak activation between 400 and $600 \mathrm{~ms}$ ) (see Figure 9).

${ }^{8}$ Peak latency for the P3a and P3b components was earlier for high capacity than average capacity subjects. This finding was confirmed by using timecourse analysis that examined whether there were differences between groups in the onset of P3a and P3b. Mean amplitude was compared under Attend vs. Ignore, and under Neutral vs. Ignore for ten $25 \mathrm{~ms}$ epochs between 350 and $650 \mathrm{~ms}$. For the P3a component (at ROIs RAM, LAM, RPM, LPM), compared to average capacity subjects, high capacity subjects exhibited an onset of significant differences between conditions that was $75 \mathrm{~ms}$ earlier for Attend vs. Ignore and $50 \mathrm{~ms}$ earlier for Neutral vs. Ignore. For the P3b component (at ROIs RPM, LPM), compared to average capacity subjects, high capacity subjects exhibited an onset of significant differences between conditions that was $50 \mathrm{~ms}$ earlier for Attend vs. Ignore and $25 \mathrm{~ms}$ earlier for Neutral vs. Ignore. Thus, the results of the time-course analysis support the notion that high capacity subjects execute the cognitive operations indexed by the P3a and P3b more quickly than average capacity subjects. 


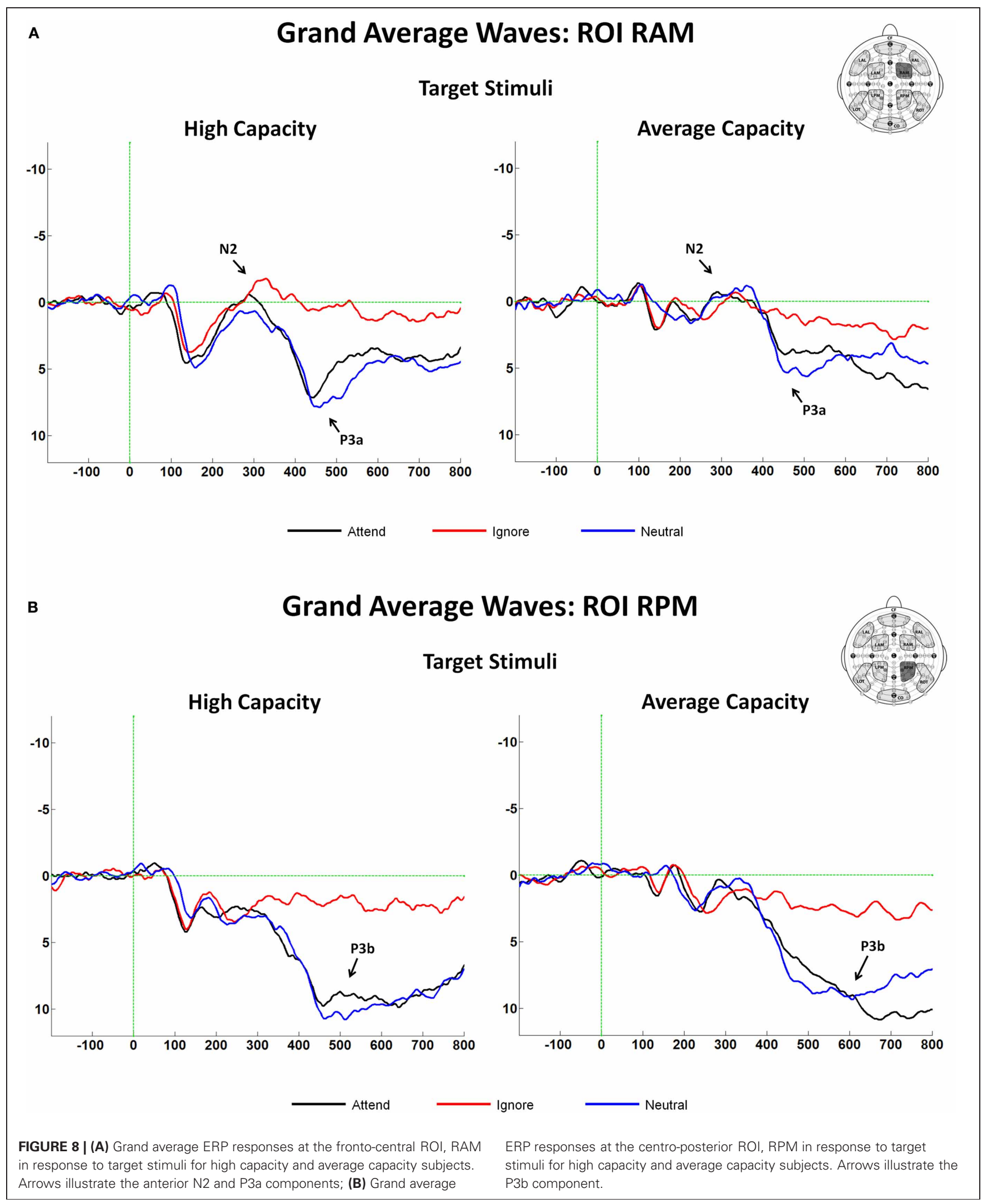




\section{Independent Component Analysis}

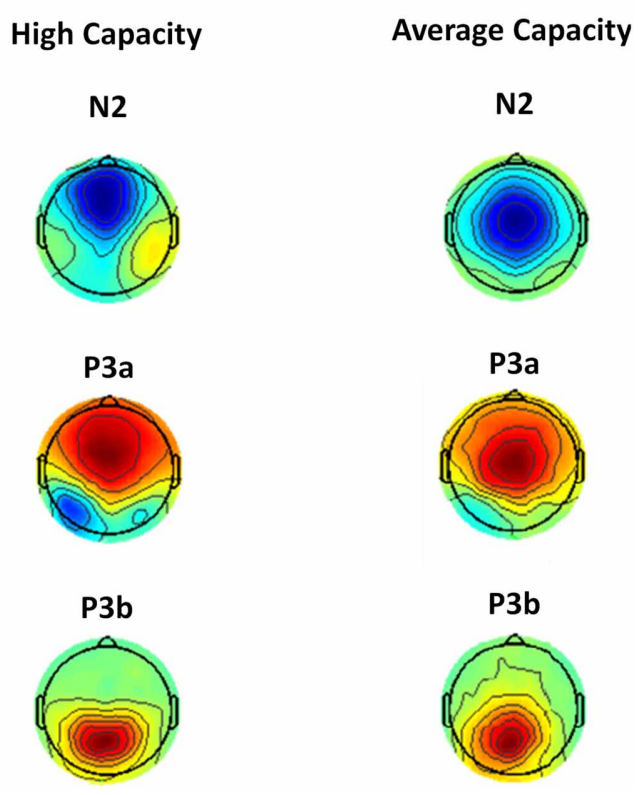

FIGURE 9 | Independent components representing the anterior N2, $\mathrm{P} 3 \mathrm{a}$, and $\mathrm{P} 3 \mathrm{~b}$ components in response to target stimuli for high capacity and average capacity subjects.

Statistical analysis was performed on the back-projected ERP activations of the two identified components. Local positive peaks of the components were measured on the grand average waves under the Attend and Neutral conditions from 350 to $650 \mathrm{~ms}$. ERP projections of the IC corresponding to the P3a component peaked at $\mathrm{Fz}$ at $432 \mathrm{~ms}$ for high capacity individuals and $527 \mathrm{~ms}$ for average capacity individuals. An ANOVA of the mean amplitude around the peak $( \pm 50 \mathrm{~ms})$ across all 10 ROIs was carried out. There was no interaction between EC and ROI $(p>0.26)$, suggesting that the scalp distribution of the ICs representing the P3a were similar for high and average capacity groups. There was a three-way interaction between EC, condition, and ROI $\left[F_{(18,414)}=3.57\right.$, $p<0.05]$. To explore this interaction, an ANOVA of the mean amplitude at five anterior ROIs was carried out separately for each EC group. For high capacity subjects, there was an effect of condition $\left[F_{(2,22)}=14.89, p<0.001\right]$ due to the mean amplitude being larger under both the Attend and Neutral conditions than under the Ignore condition, with no difference between the Attend and Neutral conditions $(A=N>I)$. In contrast, for average capacity subjects, there was no effect of condition $(A=N=I$, $p>0.35$ ). ERP projections of the IC corresponding to the $\mathrm{P} 3 \mathrm{~b}$ component peaked at $\mathrm{Pz}$ at $469 \mathrm{~ms}$ for high capacity individuals and $604 \mathrm{~ms}$ for average capacity individuals. An ANOVA of the mean amplitude around the peak $( \pm 50 \mathrm{~ms})$ across all 10 ROIs was carried out. There was no interaction between EC and ROI $(p>0.15)$ or between EC, condition, and ROI $(p>0.14)$. ANOVA comparisons of mean amplitude measured at the five posterior ROIs revealed that both the high and average capacity groups exhibited the same pattern $(\mathrm{A}=\mathrm{N}>\mathrm{I})$. There was an effect of condition for the high capacity group $\left[F_{(2,22)}=21.72\right.$, $p<0.0001]$ and for the average capacity group $\left[F_{(2,24)}=39.29\right.$, $p<0.0001]$.

In summary, IC analysis confirmed the pattern of results obtained through traditional measures of ERPs: P3 latencies for average capacity individuals were delayed relative to high capacity individuals. For the P3a, high performers generated a substantially smaller amplitude under the Ignore condition than under the other two conditions $(\mathrm{A}=\mathrm{N}>\mathrm{I})$, whereas the average performers failed to do so $(\mathrm{A}=\mathrm{N}=\mathrm{I})$. For the $\mathrm{P} 3 \mathrm{~b}$ amplitude, the two groups exhibited a similar pattern of response across conditions $(\mathrm{A}=\mathrm{N}>\mathrm{I})$.

\section{Regression analyses}

Because we found that subjects with average EC exhibited a prolonged SN latency, we were interested in evaluating whether this marker of suboptimal filtering might account for reduced cognitive control (indexed by the anterior N2) or increased orienting of attention (indexed by the $\mathrm{P} 3 \mathrm{a}$ ) in response to target-like stimuli. Regression analyses revealed that the SN latency did not predict the size of the anterior N2 (I-N), the size of the P3a difference wave (A-I, N-I), or the latency of the P3 (Attend, midline sites) to target stimuli.

The relationship between EC and different indices of information processing was also examined. Consistent with the ANOVA findings, EC was not associated with the size of the anterior SP component or posterior SN component. In contrast, EC predicted SN latency $\left(r^{2}=0.17, r=-0.41, p<0.05\right)$ and P3 latency (Attend, midline sites) $\left(r^{2}=0.16, r=-0.40, p<0.05\right)$ : the higher the EC, the shorter the SN latency and the shorter the P3 latency ${ }^{9}$ (see Figure 10). EC also predicted the difference in the size of the anterior N2 (I-N) component to target stimuli $\left(r^{2}=0.26, r=-0.51, p<0.01\right)$ and the size of the P3a difference waves to target stimuli (A-I, N-I) $\left(r^{2}=0.19, r=0.43\right.$, $p<0.04)$ : the higher EC, the larger the difference between conditions in the amplitude of the anterior N2 and the P3a. The correlation between these variables remained significant after controlling for SN latency, suggesting that the link between EC and either cognitive control or conscious orienting was not mediated by SN latency.

Multiple regression techniques were used to explore potential models of factors contributing to the variance in EC. SN latency and P3 latency (Attend, midline sites) contributed independently to the variance in EC. Together they accounted for 34\% of the variance of EC $\left(r^{2}=0.34, r=0.59, p<0.01\right.$; P3 latency standardized $\beta$ coefficient $=-0.42, p<0.03$; SN latency standardized $\beta$ coefficient $=-0.43, p<0.03)$. By adding the anterior $\mathrm{N} 2(\mathrm{I}-\mathrm{N})$ to the model as an independent variable, even more of the variance of EC was explained $\left(r^{2}=0.45, r=0.67, p<\right.$ 0.005 ; P3 latency standardized $\beta$ coefficient $=-0.35, p=0.05$; $\mathrm{SN}$ latency standardized $\beta$ coefficient $=-0.33, p<0.07 ; \mathrm{N} 2$ amplitude standardized $\beta$ coefficient $=-0.35, p=0.05)$.

${ }^{9}$ The same relationship was observed for the P3 latency (Attend) at $\mathrm{Pz}$ alone $\left(r^{2}=0.17, r=-0.41, p<0.05\right)$, and for the P3 latency measured as a difference wave, Attend - Ignore at $\mathrm{Pz}\left(r^{2}=0.19, r=-0.44, p<0.03\right)$ or at midline sites $\left(r^{2}=0.17, r=-0.41, p<0.03\right)$. 


\section{ERP Latencies vs. Executive Capacity}
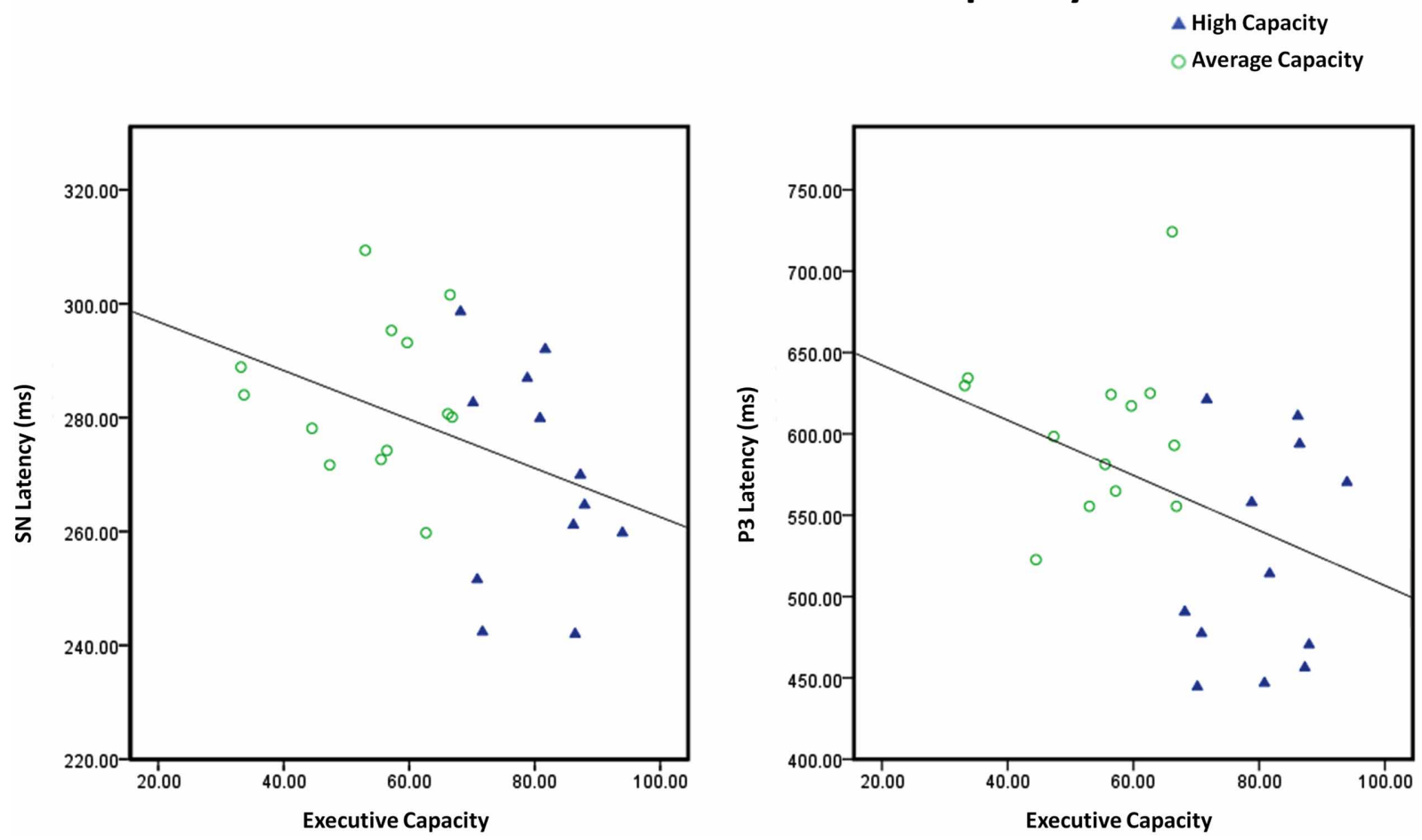

FIGURE 10 | Scatter plots illustrating that the inverse relationships between executive capacity and both SN and P3 latencies were continuous. Executive capacity = composite (mean percentile) score on tests of executive function. Note that there are different scales for SN latency and P3 latency.

Finally, we used regression analyses to identify variables that made important contributions to behavioral performance. EC appeared to explain a portion of the variance in mean RT to targets under the SA condition $\left(r^{2}=0.15, r=-0.39, p=0.05\right)$ : the higher the EC, the shorter the RT to targets. However, this relationship did not remain significant after adding $\mathrm{SN}$ latency or P3 latency to the model as independent variables. SN latency and $\mathrm{P} 3$ latency tended to make independent contributions to target RT $\left(r^{2}=0.38, r=0.61, p<0.02\right.$; SN latency standardized $\beta=0.36, p<0.08$; P3 latency (difference waves, midline) standardized $\beta=0.44, p<0.03$ ). EC did not contribute to the model. In contrast, EC explained a large portion of the variance in performance accuracy on the SA task $\left(r^{2}=0.23, r=0.48, p<0.02\right)$, while $\mathrm{SN}$ latency and $\mathrm{P} 3$ latency did not contribute to the variance [Of note, although the anterior N2 (I-N) also tended to predict accuracy $\left(r^{2}=0.12, r=-0.35, p<0.09\right)$, this variable did not contribute to the overall model].

\section{DISCUSSION}

A major goal of this research was to test the hypothesis that individuals with higher EC would exhibit more robust markers of SA, as indexed by the SP and the SN. The inclusion of a color-neutral condition allowed for further evaluation of whether the expected difference between high and average capacity individuals in the SP and $\mathrm{SN}$ was primarily explained by the diminished ability of average capacity individuals to inhibit neural activity under the Ignore relative to the Neutral condition. We expanded upon previous research by deriving an estimate of EC based on a set of neuropsychological tests rather than performance on the particular experimental task employed, and by examining the relationship between individual differences in EC and traditional ERP measures of both early SA (the SP and SN) and later processing (anterior N2 and P3).

Contrary to the hypotheses generated, we found no differences in amplitude between the high and average capacity groups in either the anterior SP or the posterior SN. In addition, the pattern of electrophysiological modulation of these early selection mechanisms was similar for both groups, with the SP and $\mathrm{SN}$ primarily reflecting reduction of neural activity under Ignore rather than augmentation of activity under Attend $(A=N>I$ for SP and $\mathrm{A}=\mathrm{N}<\mathrm{I}$ for $\mathrm{SN}$ ). Thus, in the current task, EC seems to have a limited impact upon the operations that mediate SA: young adults with average and high EC carry out the same basic SA mechanisms, as measured by the size and pattern of the electrophysiological response of the SP and SN. However, average capacity subjects appear to do so less efficiently, as measured by the delayed SN latency. Regression analyses further revealed that the inverse relationship between the EC and SN latency was continuous.

The failure to filter irrelevant information in a timely manner could be interpreted as supportive of the hypothesis under scrutiny. A critical question is whether the magnitude of this delay is clinically or functionally meaningful. Stated differently, were there costs associated with the delays in early selection 
operations that were observed in average capacity individuals? Do they account for suboptimal execution of later stages of information processing? In theory, the inefficiencies in SA may undermine the quality of information available for subsequent operations and partially explain the reduced generation of control mechanisms (anterior N2) and the excessive orienting of attention in response to target-like stimuli under the Ignore condition (P3a), as will be reviewed in the next section. However, regression analyses provided limited support for this mechanism. For example, SN latency did not predict the size of either the anterior N2 or the P3a difference waves to target stimuli. Moreover, the relationship between the anterior N2 amplitude and EC, or between the P3a difference wave and EC survived after controlling for SN latency. Despite these observations, we are not inclined to dismiss the relevance of the prolonged $\mathrm{SN}$ latency. It appears to make an independent contribution to delays in RT, and may have negatively impacted cognitive operations not measured in this investigation.

The results of our study strongly suggest that EC is closely linked to measures of cognitive control, the conscious orienting of attention, and speed of processing. As noted in the in the Introduction, there were competing hypotheses about possible results for the anterior N2. The study found that individuals with high EC exhibit a larger anterior N2 under situations that require cognitive control to manage potential response conflict. Specifically, they generated a bigger anterior N2 to target-like stimuli under the Ignore condition than under the Attend or the Neutral condition, which did not differ $(\mathrm{I}<\mathrm{A}=\mathrm{N})$, whereas average capacity performers did not modulate the anterior N2 response across conditions $(\mathrm{I}=\mathrm{A}=\mathrm{N})$. The fact that ICA yielded the same outcome as the analysis of grand average waves argues against the notion that the anterior N2 findings are simply due to an overlapping anterior positivity (e.g., a larger P3a response among average capacity subjects to target-like stimuli under the Ignore condition). Regression analyses revealed that the relationship between EC and the anterior N2 (I-N) was continuous: the higher the EC, the larger the difference in the size of the N2 across conditions. Our findings add to the literature that has tended to examine differences in the anterior N2 component between high and low performers on a specific experimental task (Falkenstein et al., 1999; Folstein and Van Petten, 2008; Fritzsche et al., 2010). Although top-down activity theoretically leads to the reduction of further perceptual processing of to-be-ignored stimuli (e.g., attenuated $\mathrm{SN}$ ), it probably does not terminate motor preparatory activity initiated by the early preliminary evaluation of stimuli that share target features. It appears that subsequent executive control operations, indexed by the anterior N2, are elicited in high capacity individuals when processing to-be-ignored stimuli. These operations may serve as a kind of insurance mechanism, helping to prevent inappropriate responses to target-like stimuli under the Ignore condition and contributing to a higher accuracy rate among high capacity subjects.

Theoretically, the orienting of attention to target stimuli under the Attend condition should be much stronger than to target-like stimuli under the Ignore condition. Our results indicate that the difference in P3a amplitude between Attend and Ignore was larger for high capacity than average capacity subjects. Regression analyses revealed a continuous relationship, with EC predicting the size of the P3a difference wave. Moreover, among average capacity subjects, the IC representing the P3a was as large under the Ignore condition as under the Attend and Neutral ones $(A=N=I)$, which is a very different pattern from high capacity subjects $(\mathrm{A}=\mathrm{N}>\mathrm{I})$.

It is striking that the preserved ability of average capacity subjects to suppress early neural responses to target letters under the Ignore condition (as measured by SP and SN components) did not prevent them from generating a relatively large orienting response to target letters (indexed by the P3a) under the Ignore compared to Attend condition. This relative increase in the size of the P3a to target-like stimuli under the Ignore condition may be due to faulty early filtering, not indexed by the SP or SN components, or reflect the need of average capacity subjects to call for additional resources to help manage the lure of distractors. An alternative interpretation of the anterior P3 in response to target-like stimuli under the Ignore condition is that it represents what has been labeled a NoGo P3 (Falkenstein et al., 1999). There is evidence to support the notion that in contrast to the NoGo N2, which reflects the detection of conflict between responding and withholding a response, the NoGo P3 indexes the actual inhibition or cancellation of a motor response (Liu et al., 2011; Randall and Smith, 2011). Within this framework, the increased size of the anterior P3 among average capacity subjects may reflect the generation of a relatively late control mechanism to suppress prepotent responses to target-like stimuli. More efficient SA operations and conflict monitoring among high capacity subjects may eliminate the need for them to exercise this kind of belated motor control. Although a contribution from a NoGo P3 cannot be ruled out, it seems to be an inadequate explanation. Neither high nor average capacity subjects generated a larger anterior P3 to NoGo, target-like events under the Ignore condition than to Go target events under the Attend condition. This pattern would be highly uncharacteristic of the anterior NoGo P3 component, which is larger to stimuli in which responses must be withheld than to stimuli in which they must be carried out.

There is a substantial body of evidence to suggest a strong inverse relationship between different measures of intellectual capacity and RT on a wide variety of tasks (Sheppard and Vernon, 2008; Neubauer and Fink, 2009). EC can have an impact upon processing speed in many ways. High capacity may be associated with more efficient manipulation of information, slower decay of data being held on-line, reduced interference from task-irrelevant events, and more skillful control of the timing and execution of different cognitive operations. In the current study, latencies of the various ERP components of interest were investigated to examine differences in the speed of processing between high and average capacity individuals.

We observed group differences in P3 latency, which is in agreement with many reports in the literature (Polich et al., 1983; Walhovd and Fjell, 2002; Walhovd et al., 2005; Riis et al., 2008). High capacity subjects generated an earlier P3 latency at both anterior (P3a) and posterior (P3b) sites, consistent with more efficiently carrying out operations associated with orienting attention and decision-making/updating. As noted earlier, high capacity individuals also generated shorter posterior SN latencies, suggestive of the ability to more quickly execute SA operations 
that occur earlier in the information processing stream. In agreement with the literature, there appeared to be a strong inverse relationship between EC and RT. However, after controlling for SN latency and P3 latency, the relationship did not remain significant. This result suggests that EC may impact target RT through the intervening variables of SN latency and P3 latency. In contrast, EC explained a large portion of the variance in performance accuracy on the task, while SN latency and P3 latency did not add to the model.

Several limitations of this study deserve further comment. Because there is no consensus about the most sensitive and appropriate tests of EC, the assignment of subjects to the high vs. average EC group may have differed if other neuropsychological tests had been employed. We tried to mitigate this concern by using a composite score from six tests. Of note, subjects performed at a relatively consistent level across the group of tests measuring executive functions. Differences between the groups were largely restricted to the realm of EC. No robust differences were found on tests of fluid intelligence, memory, language, or visual perception, reducing the likelihood that the experimental findings were a reflection of these other cognitive realms. It would be interesting for future studies to examine the relationship between individual components of executive function (e.g., maintenance, monitoring, or manipulation/control) and experimental measures of SA and subsequent processing to determine if this approach is more informative than using a composite score.

The extent to which inferences about the role of EC in SA are constrained by specific aspects of the current experimental task remains to be determined. In contrast to other studies (e.g., Vogel and Machizawa, 2004; Vogel et al., 2005; Rutman et al., 2010), the to-be-attended and to-be-ignored stimuli in the current paradigm were presented sequentially rather than simultaneously, which may not have taxed SA mechanisms sufficiently to observe a difference between high and average capacity individuals. Additionally, only one level of working memory demand (five letters) was presented. It is plausible that differences between high and average capacity individuals in measures of SA might emerge across various levels of WM demand. It is important

\section{REFERENCES}

American Psychiatric Association. (1994). Diagnostic and Statistical Manual of Mental Disorders, 4th Edn. Washington, DC: American Psychiatric Association.

Barcelo, F., Escera, C., Corral, M. J., and Perianez, J. A. (2006). Task switching and novelty processing activate a common neural network for cognitive control. J. Cogn. Neurosci. 18, 1734-1748.

Beck, A. T., and Steer, R. A. (1987). Beck Depression Inventory: Manual. San Antonio, TX: The Psychological Corporation.

Bell, A. J., and Sejnowski, T. J. (1995). An information-maximization approach to blind separation and blind deconvolution. Neural Comput. 7, 1129-1159.

Benton, A. L., Hamsher, K., and Sivan, A. B. (1994). Multilingual Aphasia Examination, Manual of Instruction. Iowa City, IA: AJA Associates.

Benton, A. L., Varney, N. R., De S.Hamsher, K., and Spreen, O. (1983). Contributions to Neuropsychological Assessment. Oxford: Oxford University Press.

Braver, T. S., Cole, M. W., and Yarkoni, T. (2010). Vive les differences! Individual variation in neural mechanisms of executive control. Curr. Opin. Neurobiol. 20, 242-250.

Cabeza, R., Anderson, N. D., Locantore, J. K., and McIntosh, A. R. (2002). Aging gracefully: compensatory to note that although the tasks employed here may not have been particularly demanding, they were sufficiently difficult to elicit differences in accuracy, reaction time, and indices of later controlled processing between groups varying in EC. However, future studies that include simultaneous presentation of relevant (attend) and irrelevant (ignore) stimuli, and that vary levels of task demand, would be helpful.

In summary, recent investigations that have highlighted a tight link between top-down control mechanisms and SA led to the expectation that individuals with high EC would exhibit more robust markers of early selection. However, results from the current study that used traditional ERP measures of SA and derived an index of EC not dependent upon the experimental task suggest a more nuanced relationship. There is no simple one-to-one mapping between measures of SA and measures of EC or controlled processing. EC did not account for the size of the SP or $\mathrm{SN}$ components. A fair degree of independence between early selection and later cognitive operations, as measured by ERPs, was observed. Despite the fact that average capacity individuals generated SP and SN amplitudes of equal size to high capacity individuals, they responded to targets under the Ignore condition with a much smaller anterior N2 and generated a much less differentiated P3a (relative to the Attend condition). Although average capacity individuals exhibited delays in carrying out SA operations ( $\mathrm{SN}$ latency), these did not account for the delays in orienting or decision making (P3 latency), or explain the excessive orienting and reduced cognitive control mechanisms in response to target-like events under the Ignore condition. Moreover, the SN latency and P3 latency made independent contributions to the variance in EC and RT. Our findings indicate that current views about the relationship between top-down control and SA may need refinement.

\section{ACKNOWLEDGMENTS}

This research was funded in part by NIA grant R01 AGO17935 and by generous support from D. Wimberly and S. Muss. The authors would like to thank Katie Gartner and Marissa Keppley for their excellent administrative assistance, and Brittany Alperin for her technical assistance. brain activity in high-performing older adults. Neuroimage 17, 1394-1402.

Chan, R. C., Shum, D., Toulopoulou, T., and Chen, E. Y. (2008). Assessment of executive functions: review of instruments and identification of critical issues. Arch. Clin. Neuropsychol. 23, 201-216.

Chong, H., Riis, J. L., McGinnis, S. M., Williams, D. M., Holcomb, P. J., and Daffner, K. R. (2008). To ignore or explore: top-down modulation of novelty processing. J. Cogn. Neurosci. 20, 120-134.

Daffner, K. R., Chong, H., Sun, X., Tarbi, E. C., Riis, J. L., McGinnis, S. M., and Holcomb, P. J. (2011). Mechanisms underlying age- and performance-related differences in working memory. J. Cogn. Neurosci. 23, 1298-1314.

Daffner, K. R., Mesulam, M. M., Scinto, L. F. M., Cohen, L. G., Kennedy, B. P., West, W. C., and Holcomb, P. J. (1998). Regulation of attention to novel stimuli by frontal lobes: an event-related potential study. Neuroreport 9, 787-791.

Daffner, K. R., Scinto, L. F. M., Weitzman, A. M., Faust, R., Rentz, D. M., Budson, A. E., and Holcomb, P. J. (2003). Frontal and parietal components of a cerebral network mediating voluntary attention to novel events. J. Cogn. Neurosci. 15, 294-313. 
Daffner, K. R., and Searl, M. M. (2007). "The dysexecutive syndromes," in Handbook of Clinical Neurology, eds B. Miller and G. Goldenberg (New York, NY: Elsevier), 249-267.

Daffner, K. R., Zhuravleva, T. Y., Sun, X., Tarbi, E. C., Haring, A. E., Rentz, D. M., and Holcomb, P. J. (2012). Does modulation of selective attention to features reflect enhancement or suppression of neural activity? Biol. Psychol. 89, 398-407.

Daselaar, S. M., and Cabeza, R. (2005). "Age-related changes in hemispheric organization," in Cognitive Neuroscience of Aging, eds R. Cabeza, L. Nyberg, and D. Park (New York, NY: Oxford University Press), 325-353.

de Fockert, J. W., Rees, G., Frith, C. D., and Lavie, N. (2001). The role of working memory in visual selective attention. Science 291, 1803-1806.

Delis, D., Kaplan, E., and Kramer, J. (2001). Delis Kaplan Executive Function System. San Antonio, TX: Psychological Cooperation.

Delorme, A., and Makeig, S. (2004). EEGLAB: an open source toolbox for analysis of single-trial EEG dynamics including independent component analysis. J. Neurosci. Methods 134, 9-21.

Delorme, A., Rousselet, G. A., Mace, M. J., and Fabre-Thorpe, M. (2004). Interaction of top-down and bottom-up processing in the fast visual analysis of natural scenes. Brain Res. Cogn. Brain Res. 19, 103-113.

Desimone, R., and Duncan, J. (1995). Neural mechanisms of selective visual attention. Annu. Rev. Neurosci. 18, 193-222.

Donchin, E., and Coles, M. G. H. (1988). Is the P300 component a manifestation of context updating? Behav. Brain Sci. 11, 357-374.

Falkenstein, M., Hoormann, J., and Hohnsbein, J. (1999). ERP components in Go/Nogo tasks and their relation to inhibition. Acta Psychol. (Amst.) 101, 267-291.

Folstein, J. R., and Van Petten, C. (2008). Influence of cognitive control and mismatch on the N2 component of the ERP: a review. Psychophysiology 45, 152-170.

Folstein, M. F., Folstein, S. E., and McHugh, P. R. (1975). "MiniMental State". A practical method for grading the cognitive state of patients for the clinician. J. Psychiatr. Res. 12, 189-198.

Friedman, D. (2003). Cognition and aging: a highly selective overview of event-related potential (ERP) data. J. Clin. Exp. Neuropsychol. 25, 702-720.
Friedman, D., Cycowicz, Y. M., and Gaeta, H. (2001). The novelty P3, an event-related brain potential (ERP) sign of the brain's evaluation of novelty. Neurosci. Biobehav. Rev. 25, 355-373.

Fritzsche, A. S., Stahl, J., and Gibbons, H. (2010). An ERP study of the processing of response conflict in a dynamic localization task: the role of individual differences in task-appropriate behavior. Clin. Neurophysiol. 121, 1358-1370.

Gazzaley, A., Clapp, W., Kelley, J., McEvoy, K., Knight, R. T., and D’Esposito, M. (2008). Age-related top-down suppression deficit in the early stages of cortical visual memory processing. Proc. Natl. Acad. Sci. U.S.A. 105, 13122-13126.

Gazzaley, A., Cooney, J. W., Rissman, J., and D'Esposito, M. (2005). Topdown suppression deficit underlies working memory impairment in normal aging. Nat. Neurosci. 8, 1298-1300.

Harter, R. M., and Aine, C. J. (1984). "Brain mechanisms of visual selective attention," in Varieties of Attention, eds R. Parasuraman and D. R. Davies (Orlando, FL: Academic Press Inc.), 293-321.

Heilman, K., and Valenstein, E. (2003). Clinical Neuropsychology. New York, NY: Oxford University Press.

Hillyard, S. A., and Anllo-Vento, L. (1998). Event-related brain potentials in the study of visual selective attention. Proc. Natl. Acad. Sci. U.S.A. 95, 781-787.

Hillyard, S. A., and Munte, T. F. (1984). Selective attention to color and location: an analysis with eventrelated brain potentials. Percept. Psychophys. 36, 185-198.

Hillyard, S. A., Teder-Salejarvi, W. A., and Munte, T. F. (1998). Temporal dynamics of early perceptual processing. Curr. Opin. Neurobiol. 8, 202-210.

Hirst, W. (1986). "The psychology of attention," in Mind and Brain: Dialogues in Cognitive Neuroscience, eds J. E. LeDoux and W. Hirst (New York, NY: Cambridge University Press), 105-141.

Ivnik, R. J., Malec, J. F., Smith, G. E., Tangalos, E. G., and Petersen, R C. (1996). Neuropsychological tests' norms above age 55, COWAT, BNT, MAE Token, WRAT-R Reading, AMNART, STROOP, TMT, and JLO. Clin. Neuropsychol. 10, 262-278.

Kahneman, D. (1973). Attention and Effort. Englewood Cliffs, NJ: Prentice-Hall.

Knight, R. T., and Scabini, D. (1998). Anatomic bases of event-related potentials and their relationship to novelty detection in humans. J. Clin. Neurophysiol. 15, 3-13.

Kok, A. (2000). Age-related changes in involuntary and voluntary attention as reflected in components of the event-related potential (ERP). Biol. Psychol. 54, 107-143.

Kok, A. (2001). On the utility of P3 amplitude as a measure of processing capacity. Psychophysiology 38, 557-577.

Kopp, B., Tabeling, S., Moschner, C., and Wessel, K. (2007). Temporal dynamics of selective attention and conflict resolution during crossdimensional Go-NoGo decisions. BMC Neurosci. 8, 68-83.

Kropotov, J. D., Ponomarev, V. A., Hollup, S., and Mueller, A. (2011). Dissociating action inhibition, conflict monitoring and sensory mismatch into independent components of event related potentials in GO/NOGO task. Neuroimage 57, 565-575.

Lavie, N., Hirst, A., de Fockert, J. W., and Viding, E. (2004). Load theory of selective attention and cognitive control. J. Exp. Psychol. Gen. 133, 339-354.

Liu, T., Xiao, T., Shi, J., and Zhao, D. (2011). Response preparation and cognitive control of highly intelligent children: a Go-Nogo eventrelated potential study. Neuroscience $180,122-128$.

Looren, D. J., Kok, A., and van Rooy, J. C. (1988). Early and late selection in young and old adults: an event-related potential study. Psychophysiology 25, 657-671.

Luck, S. J., Woodman, G. F., and Vogel, E. K. (2000). Event-related potential studies of attention. Trends Cogn. Sci. 4, 432-440.

Luck, S., and Hillyard, S. A. (1994). Electrophysiological correlates of feature analysis during visual search. Psychophysiology 31, 291-308.

Neubauer, A. C., and Fink, A. (2009). Intelligence and neural efficiency. Neurosci. Biobehav. Rev. 33, 1004-1023.

Neville, H. J., and Lawson, D. (1987). Attention to central and peripheral visual space in a movement detection task: an event-related potential and behavioral study. II. Congenitally deaf adults. Brain Res. 405, 268-283

Nieuwenhuis, S., Yeung, N., van den Wildenberg, W., and Ridderinkhof, K. R. (2003). Electrophysiological correlates of anterior cingulate function in a go/no-go task: effects of response conflict and trial type frequency. Cogn. Affect. Behav. Neurosci. 3, 17-26.
Onton, J., Westerfield, M., Townsend, J., and Makeig, S. (2006). Imaging human EEG dynamics using independent component analysis. Neurosci. Biobehav. Rev. 30, 808-822.

Polich, J., Howard, L., and Starr, A. (1983). P300 latency correlates with digit span. Psychophysiology 20, 665-669.

Potts, G. F., and Tucker, D. M. (2001). Frontal evaluation and posterior representation in target detection. Brain Res. Cogn. Brain Res. 11, 147-156.

Randall, W. M., and Smith, J. L. (2011) Conflict and inhibition in the cuedGo/NoGo task. Clin. Neurophysiol. 122, 2400-2407.

Reitan, R., and Wolfson, D. (1985). The Halstead-Reitan Neuropsychological Test Battery: Theory and Clinical Interpretation. Tucson, AZ: Neuropsychology Press.

Riis, J. L., Chong, H., McGinnnis, S., Tarbi, E., Sun, X., Holcomb, P. J., Rentz, D. M., and Daffner, K. R. (2009). Age-related changes in early novelty processing as measured by ERPs. Biol. Psychol. 82, 33-44.

Riis, J. L., Chong, H., Ryan, K. K., Wolk, D. A., Rentz, D. M., Holcomb, P. J., and Daffner, K. R. (2008). Compensatory neural activity distinguishes different patterns of normal cognitive aging. Neuroimage 39, 441-454.

Rutman, A. M., Clapp, W. C., Chadick, J. Z., and Gazzaley, A. (2010). Early top-down control of visual processing predicts working memory performance. J. Cogn. Neurosci. 22, 1224-1234.

Ryan, J., and Paolo, A. (1992). A screening procedure for estimating premorbid intelligence in the elderly. Clin. Neuropsychol. 6, 53-62.

Sawaki, R., and Katayama, J. (2008). Top-down directed attention to stimulus features and attentional allocation to bottom-up deviations. J. Vis. 8, 4-8.

Sheppard, L., and Vernon, P. (2008). Intelligence and speed of information-processing: a review of 50 years of research. Pers. Individ. Dif. 44, 535-551.

Sirevaag, E. J., Kramer, A. F., Coles, M. G., and Donchin, E. (1989). Resource reciprocity: an eventrelated brain potentials analysis. Acta Psychol. (Amst.) 70, 77-97.

Spreen, O., and Strauss, E. (1998). A Compendium of Neuropsychological Tests: Administration, Norms, and Commentary. New York, NY: Oxford University Press.

Tombaugh, T. N., and Hubley, A. M. (1997). The 60-item Boston Naming 
test: norms for cognitively intact adults aged 25 to 88 years. J. Clin. Exp. Neuropsychol. 19, 922-932.

Vogel, E. K., and Machizawa, M. G. (2004). Neural activity predicts individual differences in visual working memory capacity. Nature 428, 748-751.

Vogel, E. K., McCollough, A. W., and Machizawa, M. G. (2005). Neural measures reveal individual differences in controlling access to working memory. Nature 438 , 500-503.

Walhovd, K. B., and Fjell, A. M. (2002). The relationship between P3 and neuropsychological function in an adult life span sample. Biol. Psychol. 62, 65-87.

Walhovd, K. B., Fjell, A. M., Reinvang, I., Lundervold, A., Fischl, B., Salat, D., Quinn, B. T., Makris, N., and Dale, A. M. (2005). Cortical volume and speed-of-processing are complementary in prediction of performance intelligence. Neuropsychologia 43, 704-713.

Wechsler, D. (1997). Wechsler Adult Intelligence Scale. WAIS-III Administration and Scoring Manual. San Antonio, TX: The Psychological Corporation.

Wechsler, D. (2008). Wechsler Adult Intelligence Scale, 4th Edn. San Antonio, TX: Pearson.

Wickens, C., Kramer, A., Vanasse, L., and Donchin, E. (1983). Performance of concurrent tasks: a psychophysiological analysis of the reciprocity of informationprocessing resources. Science 221, 1080-1082.

Wijers, A. A., Mulder, G., Okita, T., Mulder, L. J., and Scheffers,
M. K. (1989). Attention to color: an analysis of selection, controlled search, and motor activation, using event-related potentials. Psychophysiology 26, 89-109.

Zanto, T. P., and Gazzaley, A. (2009). Neural suppression of irrelevant information underlies optimal working memory performance. J. Neurosci. 29, 3059-3066.

Zanto, T. P., Toy, B., and Gazzaley, A. (2010). Delays in neural processing during working memory encoding in normal aging. Neuropsychologia $48,13-25$.

Conflict of Interest Statement: The authors declare that the research was conducted in the absence of any commercial or financial relationships that could be construed as a potential conflict of interest.

Received: 16 February 2012; accepted: 23 May 2012; published online: 12 June 2012.

Citation: Daffner KR, Tarbi EC, Haring AE, Zhuravleva TY, Sun X, Rentz DM and Holcomb PJ (2012) The influence of executive capacity on selective attention and subsequent processing. Front.

Hum. Neurosci. 6:167. doi: 10.3389/ fnhum.2012.00167

Copyright (C) 2012 Daffner, Tarbi, Haring, Zhuravleva, Sun, Rentz and Holcomb. This is an open-access article distributed under the terms of the Creative Commons Attribution Non Commercial License, which permits noncommercial use, distribution, and reproduction in other forums, provided the original authors and source are credited. 